\title{
Regulation of the inflammatory profile of stromal cells in human breast cancer: prominent roles for TNF- $\alpha$ and the NF-KB pathway
}

Christina Katanov $^{1 \dagger}$, Shalom Lerrer ${ }^{1 \dagger}$, Yulia Liubomirski $^{1}$, Leonor Leider-Trejo ${ }^{2}$, Tsipi Meshel ${ }^{1}$, Jair Bar ${ }^{3}$, Rotem Feniger-Barish ${ }^{3}$, Iris Kamer ${ }^{3}$, Gali Soria-Artzi ${ }^{1}$, Hadar Kahani ${ }^{1}$, Debabrata Banerjee ${ }^{4+}$ and Adit Ben-Baruch ${ }^{{ }^{*+}}$

\begin{abstract}
Introduction: Breast cancer progression is promoted by stromal cells that populate the tumors, including cancer-associated fibroblasts (CAFs) and mesenchymal stem/stromal cells (MSCs). The activities of CAFs and MSCs in breast cancer are integrated within an intimate inflammatory tumor microenvironment (TME) that includes high levels of tumor necrosis factor a (TNF- $a$ ) and interleukin $1 \beta$ (IL-1 $\beta$ ). Here, we identified the impact of TNF- $\alpha$ and IL-1 $\beta$ on the inflammatory phenotype of CAFs and MSCs by determining the expression of inflammatory chemokines that are well-characterized as pro-tumorigenic in breast cancer: CCL2 (MCP-1), CXCL8 (IL-8) and CCL5 (RANTES).

Methods: Chemokine expression was determined in breast cancer patient-derived CAFs by ELISA and in patient biopsies by immunohistochemistry. Chemokine levels were determined by ELISA in (1) human bone marrow-derived MSCs stimulated by tumor conditioned media (Tumor CM) of breast tumor cells (MDA-MB-231 and MCF-7) at the end of MSC-to-CAF-conversion process; (2) Tumor CM-derived CAFs, patient CAFs and MSCs stimulated by TNF-a (and IL-1 $\beta$ ). The roles of AP-1 and NF-KB in chemokine secretion were analyzed by Western blotting and by siRNAs to c-Jun and p65, respectively. Migration of monocytic cells was determined in modified Boyden chambers.

Results: TNF- $\alpha$ (and IL-1 $\beta$ ) induced the release of CCL2, CXCL8 and CCL5 by MSCs and CAFs generated by prolonged stimulation of MSCs with Tumor CM of MDA-MB-231 and MCF-7 cells. Patient-derived CAFs expressed CCL2 and CXCL8, and secreted CCL5 following TNF-a (and IL-1 $\beta$ ) stimulation. CCL2 was expressed in CAFs residing in proximity to breast tumor cells in biopsies of patients diagnosed with invasive ductal carcinoma. CCL2 release by TNF-a-stimulated MSCs was mediated by TNF-RI and TNF-RII, through the NF-KB but not via the AP-1 pathway. Exposure of MSCs to TNF-a led to potent CCL2-induced migration of monocytic cells, a process that may yield pro-cancerous myeloid infiltrates in breast tumors.

Conclusions: Our novel results emphasize the important roles of inflammation-stroma interactions in breast cancer, and suggest that NF-KB may be a potential target for inhibition in tumor-adjacent stromal cells, enabling improved tumor control in inflammation-driven malignancies.
\end{abstract}

\section{Introduction}

The development and progression of breast tumors are multifactorial processes that are influenced by the tumor microenvironment (TME). Recent studies demonstrated that breast tumors are populated by myofibroblasts that express pro-cancerous functions [1-4], known as cancer-

\footnotetext{
* Correspondence: aditbb@tauex.tau.ac.il

${ }^{\dagger}$ Equal contributors

'Department of Cell Research and Immunology, George S. Wise Faculty of Life Sciences, Tel Aviv University, P.O. Box 39040, Tel Aviv 6997801, Israel Full list of author information is available at the end of the article
}

associated fibroblasts (CAFs). Various origins of these cells may exist, including resident tissue fibroblasts and mesenchymal stem/stromal cells (MSCs) that have been continuously exposed to tumor-derived and TME constituents. Such MSCs, originating in bone marrow (BM) or adipose tissues generally have pro-cancerous effects that promote malignancy in many tumor systems, including breast cancer [5-12]. In vitro, tumor cell products that are present in tumor-derived conditioned medium (CM) convert MSCs to CAFs which become

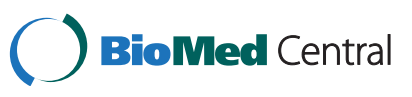


fully and potently functional in promoting malignancy in vivo [11-14].

The activities of CAFs and MSCs do not take place in the void, but rather are integrated in their intimate TME. In many cancers, the TME is dominated by inflammatory elements, including inflammatory leukocytes and inflammatory soluble factors that generally promote disease progression [15-18]. The inflammatory cytokines tumor necrosis factor alpha (TNF- $\alpha$ ) and interleukin $1 \beta$ (IL-1 $\beta)$ are often present in the inflammatory milieu of many tumors. In contrast to tumor-cytotoxic effects caused by acute local TNF- $\alpha$ administration, chronic and persistent presence of TNF- $\alpha$ in tumors has strong protumoral effects in many cancers [19-21]. Accordingly, inhibition of TNF- $\alpha$ or its receptors has prominent antitumor effects in animal models of breast cancer [22-29]. In parallel, major causative pro-tumoral roles were attributed to IL- $1 \beta$ in breast cancer via angiogenesis and matrix-remodeling activities [30-37]. Overall, based on recent studies addressing the roles of TNF- $\alpha$ and IL- $1 \beta$ in malignancy, both cytokines are now considered potential targets for therapy in cancer [32,38-40].

We recently reported that TNF- $\alpha$ and IL- $1 \beta$ were minimally expressed by normal breast epithelial cells, but were highly expressed in tumor cells of biopsies from most breast cancer patients [41]. In such individuals, the elevated expression of TNF- $\alpha$ and IL- $1 \beta$ was significantly correlated with relapse and advanced disease [41-49]. Despite emerging information on the impact of these inflammatory cytokines on tumor-promoting events in stromal cells $[10,50-55]$, their ability to shape the inflammatory phenotype of CAFs and MSCs has been only partly revealed.

Recent studies indicate that CAFs and MSCs promote malignancy through the expression of inflammatory chemokines [4,54-65]. In this respect, inflammatory chemokines such as CCL2 (monocyte chemoattractant protein 1 MCP-1), CXCL8 (IL-8) and CCL5 (RANTES) are of major relevance because they promote aggressiveness in tumor cells, they induce tumor-supporting effects in cells of the TME, and they play direct roles in advancing tumor growth and metastasis in many cancer diseases, including cancer of the breast [21,66-70]. MSC-derived and CAF-derived inflammatory chemokines promote tumor progression by inducing the infiltration of protumorigenic myeloid cells to tumors (such as tumorassociated macrophages (TAMs) and myeloid-derived suppressor cells (MDSCs) [17,67,71-75]), increasing angiogenesis, elevating tumor cell stemness, invasion and proliferation, and promoting the recruitment of MSCs to primary tumors and metastases [4,54-65]. Overall, the outcome of such chemokine activities is a pronounced promotion of cancer progression and tumor cell dissemination to distant organs.
Our overall goal in this study was to investigate aspects of inflammation-stroma interactions in breast cancer. To this end, we determined the influence of breast tumor-derived factors and of inflammatory cytokines on the inflammatory phenotype of CAFs and MSCs, manifested by the release of the pro-cancerous chemokines CCL2, CXCL8 and CCL5 by these cells. The novel findings obtained in this study show intensive inflammation-stroma interactions that act specifically through the designated pathway of nuclear factor $\mathrm{\kappa B}(\mathrm{NF}-\mathrm{kB})$ activation in stromal cells. Through these interactions, the inflammatory microenvironment shapes the tumor-promoting phenotype of MSCs and CAFs and may thus enhance tumor progression.

\section{Methods}

\section{Breast tumor cell cultures}

Human breast tumor MDA-MB-231 cells were obtained from ATCC (Manassas, VA, USA) and MCF-7 cells were kindly provided by Prof. Kaye, Weizmann Institute of Science, Rehovot, Israel. The MCF-7 cells were authenticated on the basis of published characteristics of MCF-7 cells $[76,77]$ by verifying that they express an active estrogen receptor alpha, respond to estrogen, express low levels of ErbB2, form tumors upon supplementation of estrogen and matrigel, and have low metastatic potential. These cells were grown in enriched Dulbecco's modified Eagle's medium (DMEM), including 10\% fetal bovine serum (FBS), $100 \mathrm{U} / \mathrm{ml}$ penicillin, $100 \mu \mathrm{g} / \mathrm{ml}$ streptomycin, $250 \mathrm{ng} / \mathrm{ml}$ amphotericin, and $4 \mathrm{mM}$ L-glutamine (Biological Industries, Beit Ha'emek, Israel).

\section{Isolation of CAFs from patient breast tumors}

CAFs were obtained from surgically resected breast tumors of patients who provided written informed consent as approved by the Institutional Review Board of Sheba Medical Center. Tissues were cut into small pieces, shaken overnight at $37^{\circ} \mathrm{C}$ in collagenase type $4(250 \mathrm{U} /$ $\mathrm{ml}$, \#S3J6523; Worthington Biochemical, Lakewood, NJ, USA) in DMEM, filtered (100 mm cell strainer; BD Biosciences, San Jose, CA, USA) and plated in DMEM supplemented with $20 \%$ FBS, $1 \mathrm{mM}$ sodium pyruvate, $2 \mathrm{mM}$ L-glutamine, minimum essential medium nonessential amino acids, antibiotics and $60 \mathrm{mM} \beta$-mercaptoethanol (Biological Industries; and Sigma-Aldrich, St. Louis, MO, USA). Cells propagated in these conditions had typical fibroblastic phenotype: their identity was verified by the absence of the epithelial marker cytokeratin and the presence of the typical mesenchymal markers vimentin, $\alpha$-smooth muscle actin ( $\alpha$ SMA), fibroblast-specific protein 1 (FSP1) and fibroblast-activation protein alpha (FAP $\alpha$ ) (Figure S1 in Additional file 1). The cells were routinely grown in medium as above or in Eagle's minimum 
essential medium supplemented with 10 to 20\% FBS with regular tissue culture additives.

Two human patient-derived CAF isolates were generated and characterized for CAF phenotype as described above. CAFs \#1 cells were derived from a lung metastasis of breast cancer and were immortalized by human telomerase reverse transcriptase (hTERT), as described previously [78]. CAFs \#2 cells were derived from a primary breast tumor of a different patient and were kept in culture without hTERT immortalization.

\section{Origins and growth of MSCs}

Two sources of human BM-derived MSCs of healthy individuals were used in the study. First, in the earlier stages of the study, human MSCs were isolated from unprocessed BM of healthy individuals obtained from Lonza (Walkersville, MD, USA; Cambrex at that time) and were cultured in mesencult medium (\#05411; Stemcell Technologies Inc., Vancouver, BC, Canada). Following establishment in culture, the isolated MSCs were cultured in $\alpha$-minimum essential medium containing $10 \%$ FBS and penicillin-streptomycin (as in [13]). In line with typical characteristics of MSCs, the isolated cells expressed CD44, CD105, CD90, HLA-ABC and Stro1, while they were negative for CD45, HLA-DR and CD11b (see [13]; data not shown), as determined by flow cytometry using FITC-labeled antibodies (BD Biosciences). Expanded cultures of human BM-derived MSCs were analyzed for adipogenic, osteogenic and myogenic differentiation in vitro, to determine multipotency (data not shown). Second, at the advanced stages of the study, fully characterized MSCs were purchased from Lonza. As indicated in Lonza's datasheet, the cells had typical MSC characteristics. They expressed CD44, CD29, CD105, and CD166 and did not express CD45, CD14 and CD34. Also, the cells can differentiate to adipogenic, chondrogenic and osteogenic lineages when cultured in the recommended differentiation medium. The cells were thawed into enriched mesencult medium (Stemcell Technologies Inc.) and then were subcultured every 5 to 7 days in enriched DMEM medium. In all cases, cell growth was continued in DMEM medium for a limited number of passages (generally up to 10 passages).

\section{Long-term growth of MSCs with Tumor CM, followed by TNF-a stimulation}

MDA-MB-231 and MCF-7 breast tumor cells were grown in enriched DMEM culture medium (as above). Tumor CM from these cancer cells was collected after 18 to 24 hours, centrifuged at $1,200 \mathrm{rpm}$ for 5 minutes and supernatants were passed through sterile filters with $0.45 \mu \mathrm{m}$ polyvinylidene difluoride membrane (Millipore, Bedford, MA, USA). MSCs were exposed to such fresh
Tumor CM twice a week for a $\sim 30$-day time period, following the protocol described in [13] that has generated CAFs which promoted tumor growth in vivo in past experiments [13]. In parallel, control MSCs from the same initiating cell stock were cultured with enriched DMEM medium. To verify the CAF-like phenotype of cells generated by this process (termed herein CAFs), in this study we used criteria of modified morphology and typical CAF markers: the expression of vimentin, upregulation of $\alpha$ SMA expression (Figure S2 in Additional file 1) and elevated expression of FSP1 (performed for MCF-7 CM only; data not shown).

CAFs obtained by stimulating MSCs for $\sim 30$ days and their control MSCs were trypsinized, centrifuged and counted. The cells were plated at equivalent density and, following an additional 24 hours of incubation, supernatants from the differentiated CAFs and from control MSCs were frozen in $-20^{\circ} \mathrm{C}$. In parallel, an aliquot of the original Tumor $\mathrm{CM}$ was frozen at $-20^{\circ} \mathrm{C}$. All supernatants were then thawed at the same time (from CAFs obtained by incubation with Tumor CM, from control MSCs that were grown for the same time period and the CM of the tumor cells themselves) for determination of CCL2, CXCL8 and CCL5 levels in these supernatants by enzyme-linked immunosorbent assay (ELISA).

In other assays, this same procedure was utilized in the presence of short stimulation by TNF- $\alpha(50 \mathrm{ng} / \mathrm{ml}$; PeproTech, Rocky Hill, NJ, USA), carried out during the last 24 hours of culture. TNF- $\alpha$ working concentrations were chosen based on criteria described next in Stimulation of MSCs by TNF- $\alpha$ or IL-1 $\beta$. As control for TNF- $\alpha$, the cells were incubated with the vehicle of the cytokine $(0.1 \%$ bovine serum albumin (BSA)). CCL2, CXCL8 and CCL5 levels in cell supernatants were determined by ELISA.

\section{Stimulation of MSCs by TNF- $\alpha$ or IL-1 $\beta$}

MSCs were cultured for 24 hours in enriched DMEM medium. The medium was then removed, and cells were incubated for 24 hours in medium containing TNF- $\alpha$ (50 $\mathrm{ng} / \mathrm{ml})$ or $\mathrm{IL}-1 \beta(500 \mathrm{pg} / \mathrm{ml})$ (PeproTech). Cytokine working concentrations were chosen based on calibrations performed in other cell systems in our laboratory and are in the accepted range used in vitro in other studies (several selected publications [79-81]). Chemokine expression in cell supernatants was determined by ELISA. In controls, we verified that the vehicle of the cytokines $(0.1 \%$ BSA) did not induce chemokine release by the MSCs.

In specific cases, neutralizing antibodies or small interfering RNAs (siRNAs) were used. For experiments with antibodies to TNF- $\alpha$ receptors, MSCs were plated in enriched DMEM medium for 24 hours. The cells were then washed and 
incubated in DMEM medium supplemented with $1 \%$ FBS, in the presence of neutralizing antibodies for tumor necrosis factor receptors TNF-RI and TNF-RII $(10 \mu \mathrm{g} / \mathrm{ml}$, \#MAB225 and \#MAB726, respectively; R\&D Systems, Minneapolis, MN, USA) or isotype-matched nonrelevant antibody control (10 $\mu \mathrm{g} / \mathrm{ml}$, \#400101; BioLegend, Roselle, San Diego, USA) for 1 hour. Antibody concentrations were chosen based on preliminary analyses, in which several concentrations of neutralizing antibodies were tested (data not shown). Following this incubation period, TNF- $\alpha$ (50 ng/ml) or its vehicle (as above) was added to cells. After 24 hours, cell supernatants were collected for ELISA assays.

For experiments with siRNAs to c-Jun or p65, MSCs were plated in enriched DMEM medium for 24 hours. The cells were then transiently transfected with siRNA to c-Jun (60 nM, \#L-003268-00; Dharmacon, Lafayette, CO, USA), siRNA to p65 (30 nM, \#MU003533-02; Dharmacon; kindly provided by Prof. Wiemann, DKFZ, Heidelberg Germany) or control siRNA (same concentrations) by Lipofectamine RNAiMAX ${ }^{\mathrm{m}}$ transfection reagent (Life Technologies, Grand Island, NY, USA) according to the manufacturer's instructions. The cells were washed and incubated in DMEM medium overnight, and then stimulated with TNF- $\alpha$ $(25 \mathrm{ng} / \mathrm{ml}$; a suboptimal concentration of TNF- $\alpha$ was used in order to facilitate detection of inhibitory effects) for 24 to 48 hours. Cell supernatants were collected for ELISA assays.

\section{MSC stimulation by CM derived from MDA-MB-231 cells, transfected with TNF- $a$-expressing vector}

MDA-MB-231 cells were transiently transfected with pcDNA3.1 vector or with the same vector coding for human TNF- $\alpha$, by ICAFectin ${ }^{\mathrm{mm}} 441$ DNA transfection reagent (InCellArt, Nantes, France) according to the manufacturer's instructions. After 24 hours, Tumor CM was harvested and TNF- $\alpha$ expression was determined by ELISA, as described below. In parallel, on the day of MDA-MB-231 cell transfection, MSCs were plated in enriched DMEM medium. The MSCs were then incubated for 24 hours with Tumor CM from MDA-MB-231 cells transfected by control vector or by TNF- $\alpha$-expressing vector, or with enriched DMEM medium as control. Part of the above MDA-MB-231 Tumor CM was frozen in $-20^{\circ} \mathrm{C}$, as was also the case for CM of MSCs alone. All CM was then thawed at the same time (from MSCs stimulated with supernatants of MDA-MB-231 cells transfected by control vector or by TNF- $\alpha$-expressing vector, from control MSCs and the CM of the tumor cells themselves). As appropriate, CCL2, CXCL8, CCL5 and TNF- $\alpha$ levels in these supernatants were determined by ELISA.

\section{Stimulation of patient CAFs by TNF- $\alpha$ and IL-1 $\beta$}

CAFs \#1 and CAFs \#2 isolates were cultured for 24 hours in CAF growth medium (as above). The cells were then washed twice in LPM starvation medium (Biological Industries), and incubated for 48 hours in LPM starvation medium in the presence of TNF- $\alpha(50 \mathrm{ng} / \mathrm{ml})$, IL-1 $\beta$ ( $500 \mathrm{pg} / \mathrm{ml})$ or cytokine vehicle (as above). CCL5 levels in the supernatants of the cells were determined by ELISA.

\section{Confocal analyses}

Human BM-derived MSCs that were grown in the absence of or in the presence of MDA-MB-231-derived or MCF-7-derived Tumor CM for $\sim 30$ days (as above) were cultured for 24 hours on sterilized cover slips at $37^{\circ} \mathrm{C}$. The cells were washed, fixed in $8 \%$ paraformaldehyde, permeabilized with $0.2 \%$ triton, blocked with $2 \%$ BSA in PBS, and then incubated with antibodies against $\alpha$ SMA (\#A-2547; Sigma-Aldrich) and vimentin (\#sc-6260; Santa Cruz Biotechnology, Santa Cruz, CA, USA). Negative controls included samples in which the primary antibodies were replaced by isotype-matched nonrelevant antibody controls (data not shown). The cells were then stained with the secondary antibodies, as appropriate. In parallel, cells were counterstained with the nuclear dye 4',6-diamidino-2-phenylindole. Cell-coated cover slips were removed from the wells, embedded in mounting gel and imaged by confocal microscopy (Zeiss LSM 510; Carl Zeiss AG, Oberkochen, Germany).

\section{Polymerase chain reactions (PCR)}

To determine the expression of human TNF receptors, total RNA was isolated by the EZ-RNA kit (\#20-400100; Biological Industries) from patient CAFs \#1 and CAFs \#2 isolates, from MSCs and from HL-60 cells that served as positive control. First-strand complementary DNA was generated using the M-MLV reverse transcriptase (\#AM2044; Ambion, Austin, TX, USA). The expression of TNF-RI (TNFRSF1A) and TNF-RII (TNFRSF1B) was determined using the following primers: TNF-RI, forward 5'-GCACTGCCGCTGCCACACT-3' and reverse 5' -AAGGCGATCTCGCAGGACG-3', expected PCR product size 1,480 base pairs; and TNF-RII, forward 5' ${ }^{\prime}$-ATGGCGCCCGTCGCCGTCT-3' and reverse 5' -CCTGGTTAACTGGGCTTCATC-3', expected PCR product size 1,390 base pairs. PCR amplification of TNF-RI was performed over 40 cycles $\left(95^{\circ} \mathrm{C}\right.$ for $20 \mathrm{sec}-$ onds, $60^{\circ} \mathrm{C}$ for 20 seconds, $72^{\circ} \mathrm{C}$ for 90 seconds). PCR amplification of TNF-RII was performed over 40 cycles $\left(95^{\circ} \mathrm{C}\right.$ for 20 seconds, $65^{\circ} \mathrm{C}$ for 20 seconds, $72^{\circ} \mathrm{C}$ for 90 seconds). The sequence of the resulting PCR products was verified as TNF-RI and TNR-II. No-template controls were negative. 


\section{Enzyme-linked immunosorbent (ELISA) assays}

ELISA assays were performed in the linear range of absorbance using standard curves generated with recombinant proteins. The ELISA for CCL2 involved mouse monoclonal antibodies (mAbs) against human CCL2 (\#500-M71; PeproTech) for coating, and biotinylated rabbit anti human CCL2 antibodies (\#500-P34Bt; PeproTech) for detection. The ELISA for CXCL8 involved mouse mAbs against human CXCL8 (\#511502; BioLegend) or rabbit polyclonal antibodies against human CXCL8 (\#500-P28; PeproTech) for coating, and biotinylated goat anti human CXCL8 antibodies (\#BAF208; R\&D Systems) or biotinylated rabbit anti human CXCL8 antibodies (\#500-P28Bt; PeproTech) for detection. The ELISA for CCL5 involved mouse mAbs against human CCL5 (\#500-M75; PeproTech) for coating, and biotinylated goat anti human CCL5 antibodies (\#BAF278; R\&D Systems) for detection. The ELISA for TNF- $\alpha$ involved mouse mAbs against human TNF- $\alpha$ (\#500-M26; PeproTech) for coating, and biotinylated rabbit anti human TNF- $\alpha$ antibodies (\#500-P31ABt; PeproTech) for detection. Following the addition of streptavidinhorseradish peroxidase, the substrate TMB/E (Chemicon, Temecula, CA, USA) was added. The reaction was stopped by addition of $0.18 \mathrm{M} \mathrm{H}_{2} \mathrm{SO}_{4}$, and was measured at $450 \mathrm{~nm}$.

\section{Immunohistochemistry}

The expression of CCL2 by CAFs in biopsies of patients diagnosed with invasive ductal carcinoma (IDC) was determined as described previously [41]. Briefly, serial sections (5 $\mu \mathrm{m}$ thick) obtained from archived paraffin blocks of patients were processed and stained by antibodies against human CCL2. Staining was evaluated by a breastcancer specialized pathologist.

\section{Western blotting}

To determine the activation of activator protein 1 (AP-1) and NF- $\mathrm{K}$, TNF- $\alpha$ stimulation was carried out at time points that were determined by preliminary kinetics analyses (based on published literature and on our experience in other cell systems; data not shown). In all of the experiments described below, control cells were incubated with the relevant vehicles of the reagents. The following primary antibodies were used: phosphorylated p65 (\#3033; Cell Signaling Technology, Danvers, MA, USA), total p65 (\#4764; Cell Signaling Technology), phosphorylated c-Jun (\#1527-s; Epitomics, Burlingame, CA, USA), total c-Jun (\#610326; BD Transduction Laboratories, San Jose, CA, USA) and IкB $\alpha$ (\#4814; Cell Signaling Technology). To determine the characteristics of patient CAFs and of Tumor CM-derived CAFs, the following primary antibodies were used: pan-cytokeratin (\#MA513203; Thermo Fisher Scientific, Waltham, MA, USA),
aSMA (\#A-2547; Sigma-Aldrich and \#ab5694; Abcam, Cambridge, UK), vimentin (\#sc-6260; Santa Cruz Biotechnology), FSP1 (\#ab12480; Abcam) and FAPa (\#sc-135069; Santa Cruz Biotechnology). Loading controls were determined using antibodies against glyceraldehyde 3phosphate dehydrogenase (GAPDH; \#ab9485; Abcam), $\beta$ tubulin (\#ab6046; Abcam) and Erk (\#sc-154; Santa Cruz Biotechnology), as indicated in the figures. After washing, the membranes were incubated with the appropriate secondary antibodies. In all cases, conventional western blot procedures were taken and membranes were subjected to enhanced chemiluminescent (ECL) solution and X-ray film.

\section{Migration of monocytic cells}

Monocytic THP-1 cells were grown in suspension in enriched RPMI medium and their migration in response to CM of MSCs, stimulated or not stimulated by TNF- $\alpha$, was determined. To this end, MSCs were stimulated by TNF- $\alpha$ (50 ng/ml) for 24 hours, while control cells were exposed to the vehicle of the cytokine $(0.1 \%$ BSA) in DMEM starvation medium. Supernatants from control and from stimulated cells were then collected and divided into groups as follows: supernatants from untreated control MSCs; supernatants from TNF- $\alpha$-stimulated MSCs, treated by neutralizing antibodies against CCL2 $(2 \mu \mathrm{g} / \mathrm{ml}$, \#MAB679; R\&D Systems); and supernatants from TNF- $\alpha-$ stimulated MSCs, treated by isotype-matched nonrelevant antibody (2 $\mu \mathrm{g} / \mathrm{ml}$, \#401201; BioLegend). Recombinant human CCL2 (rhCCL2) was used at $100 \mathrm{ng} / \mathrm{ml}$ as positive control in the migration assays. rhCCL2 was either untreated or treated by neutralizing antibodies against CCL2 (as above). All antibody treatments were performed for 30 minutes at $37^{\circ} \mathrm{C}$. The migration of human THP- 1 monocytic cells in response to these cell supernatants was assessed by a 48-well modified Boyden chamber through a polycarbonate polyvinylidene difluoride (PVDF) filter (8 $\mu \mathrm{m}$ pore size; Osmonics, Livermore, CA, USA). After 2 hours, the filters were fixed by methanol, and stained with a Diff-Quik kit (Dade Behring, Dudingen, Switzerland). The cells were counted in five high-power fields (HPF) by light microscopy in triplicate.

\section{Statistical analyses}

Student's $t$ test was used to calculate $P$ values for ELISAs and chemotaxis assays. $P<0.05$ was considered significant. Adjustment for multiplicity of comparisons was done using the Benjamini-Hochberg procedure. Using this procedure, all of the significant results that were presented in the manuscript remained statistically significant after correcting for their multiplicity. The ELISA results presented in the paper show a representative experiment out of $n \geq 3$ independent experiments that 
have shown similar trends. An exception is shown in Figure 1A3,B2,B3, where the effect of Tumor CM on chemokine release was not consistent; therefore, in these cases, the results are presented as mean \pm standard deviation of the different experiments (MSCs were given the value of 1). The confocal pictures are representatives of many pictures that were taken in at least three independent experiments.

\section{Results and discussion}

The effects of long-term stimulation of MSCs by Tumor $\mathrm{CM}$ on the inflammatory nature of the resulting CAFs

Published reports indicate that prolonged stimulation of BM-derived human MSCs with breast tumor-derived factors (Tumor CM) has led to conversion of MSCs into functional CAFs that promoted tumor growth [11-14]. We began this study by determining the influence of such tumor-derived factors on the inflammatory traits of CAFs generated by MSCs exposed to Tumor $\mathrm{CM}$, using the expression of the inflammatory/ pro-malignancy chemokines CCL2, CXCL8 and CCL5 as readouts. To this end, we followed our published procedure on generation of CAFs that are functional in vivo in promoting breast cancer [13], by stimulating MSCs with Tumor CM for $\sim 30$ days. Following such stimulation with Tumor CM of MDA-MB-231 and MCF-7 breast tumor cells, the resulting cells have undergone conversion to CAF-like cells (to be termed herein CAFs), as expected (Figure S2 in Additional file 1) $[12,13,82,83]$.

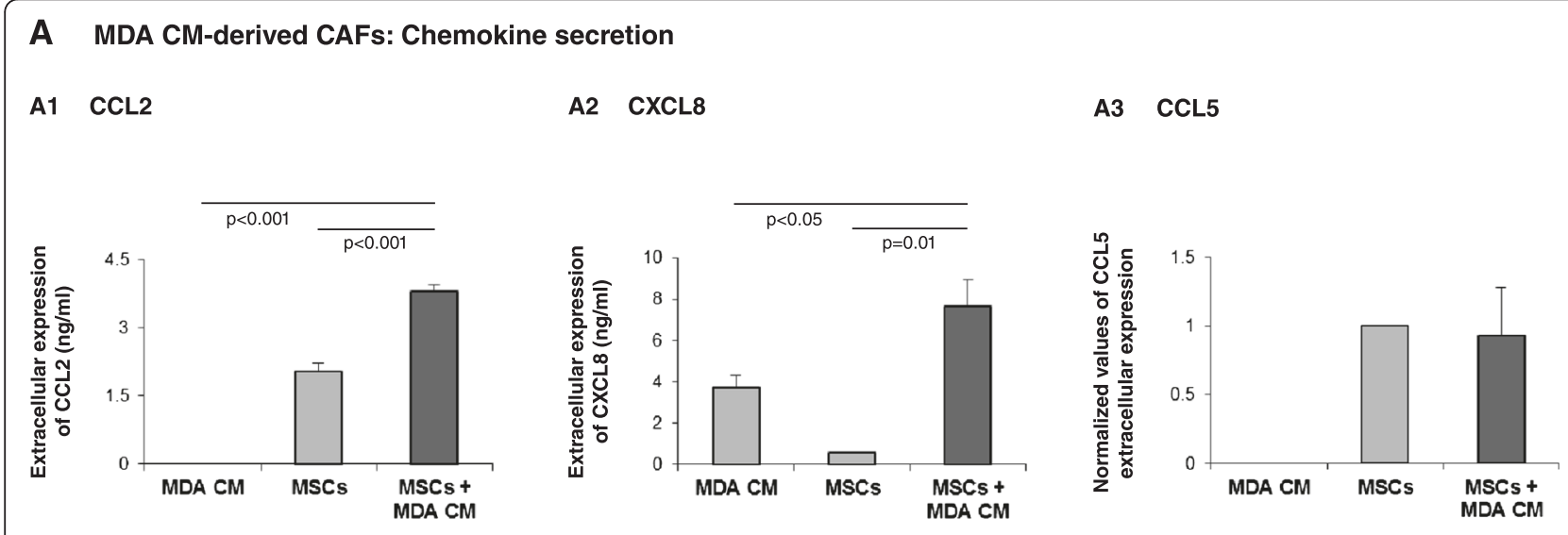

B MCF-7 CM-derived CAFs: Chemokine secretion

B1 CCL2

B2 CXCL8

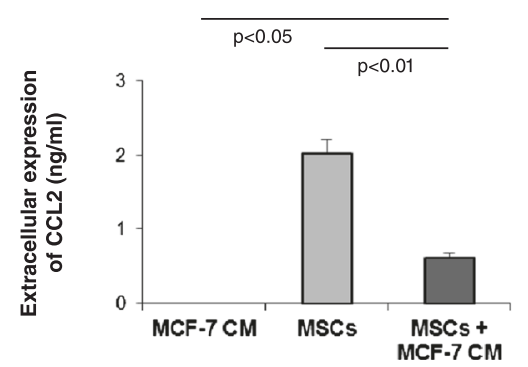

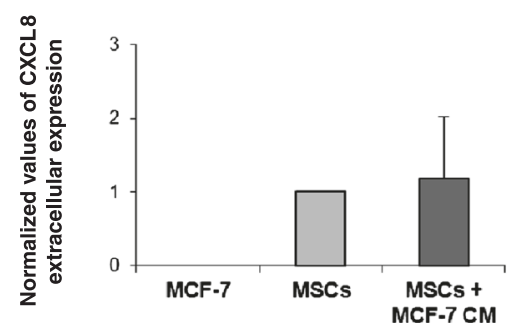

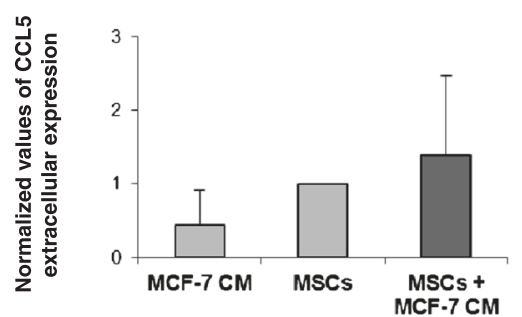

Figure $1 \mathrm{Impact}$ of prolonged stimulation by Tumor CM on the release of inflammatory chemokines by the resulting CAFs. Human BM-derived MSCS were cultured with Tumor CM from MDA-MB-231 cells (MDA) (A) or MCF-7 cells (B) over a prolonged period of time ( 30 days; MSCS + MDA CM or MSCs + MCF-7 CM, respectively). Twenty-four hours after medium exchange to fresh Tumor CM, cell supernatants were collected and the expression of CCL2 (A1, B1), CXCL8 (A2, B2) and CCL5 (A3, B3) was determined in comparison with supernatants of MSCs that were not supplemented with CM (MSCs) and with the original Tumor CM of MDA-MB-231 or MCF-7 cells alone (MDA CM or MCF-7 CM, respectively). Chemokine expression was determined by ELISA, in the linear range of absorbance. (A1), (A2), (B1) Representatives of $n=3$ independent experiments that have shown similar results. (A3), (B2), (B3) Ratios between MSCs and MSCS + Tumor CM were not consistent in different experimental repeats. Therefore, in these panels, the findings are presented as mean \pm standard deviation of normalized values (MSCs were given the value of 1) obtained in relevant experimental repeats (at least $n=3$ ). 
The generation of such CAFs by Tumor CM has been only partly accompanied by enhanced inflammatory profile of the resulting CAFs. Tumor CM of MDA-MB-231 cells has increased the release of CCL2 and CXCL8 but not of CCL5 (Figure 1A), while Tumor CM of MCF-7 cells did not promote the release of CXCL8 and CCL5 by the Tumor CM-generated CAFs (Figure 1B2,B3) and downregulated the expression of CCL2 by the cells (Figure 1B1). These results indicate that when CAFs are generated by exposure to breast tumor-derived factors, the process leads to only marginal increases in the inflammatory phenotype of the resulting CAFs. Moreover, only the CM of the more aggressive MDA-MB-231 breast tumor cells upregulated chemokine production by the resulting CAFs, revealing heterogeneity in the content of the factors produced by different breast tumor cells and in their impact on the expression of inflammatory traits by CAFs. The content of Tumor CM is complex (for example $[6,62,84]$ ); thus, the identity of the factors regulating the expression of the different chemokines is yet to be explored and the question of whether these same factors also induce the conversion of MSCs to CAFs needs to be addressed in future studies.

\section{TNF- $a$ prominently induces the release of pro-cancerous} chemokines by Tumor CM-generated CAFs and by patient CAFs

TNF- $\alpha$ and IL-1 $\beta$ are highly expressed by cancer cells of patients in human breast tumors (and also by adjacent stromal cells and leukocytes). Of the two cytokines, TNF- $\alpha$ is of particular interest because of its divergent and at times opposing roles in the TME, and also because it induces the release of inflammatory chemokines by breast tumor cells and normal tissue cells (for example $[41,85-87])$. Also, as we show in Figure S3 in Additional file 1, the expression of TNF-RI and TNF-RII was denoted in MSCs. Thus, we questioned what is the impact of TNF- $\alpha$ on the inflammatory traits of CAFs derived from MSCs stimulated by Tumor CM. Breast tumor cells are known to lose in culture the capacity to release endogenous inflammatory cytokines, such as TNF- $\alpha$ or IL-1 $\beta$ (lack of endogenous TNF- $\alpha$ expression is shown in Figure S4 in Additional file 1, under nontransfected and control vector cells; results for IL-1 $\beta$ are not shown). Therefore, we have used exogenous TNF- $\alpha$ for stimulating the CAFs that were generated from MSCs by Tumor CM. We then determined the release of the inflammatory chemokines by the stimulated cells (Figure 2).

To determine the effects of TNF- $\alpha$ stimulation on Tumor CM-generated CAFs, MSCs that were exposed to Tumor CM for $\sim 30$ days were stimulated by TNF- $\alpha$ during the last 24 hours of culture (MSCs + MDA CM + TNF- $\alpha$ or MSCs + MCF-7 CM + TNF- $\alpha$ ) followed by determination of CCL2, CXCL8 and CCL5 expression in cell supernatants. In parallel, chemokine expression was determined in MSCs that were exposed to Tumor CM alone for the same prolonged time period (MSCs + MDA CM or MSCs + MCF-7 CM) and in MSCs that were grown in culture for $\sim 30$ days without Tumor $\mathrm{CM}$ and were then stimulated by TNF- $\alpha$ during the last 24 hours (MSCs + TNF- $\alpha$ ). The results shown in Figure 2 demonstrate that when CAFs were generated by prolonged exposure of MSCs to Tumor CM, the resulting CAFs responded to TNF- $\alpha$ by elevated release of CCL2, CXCL8 and CCL5. In parallel, stimulation of MSCs by TNF- $\alpha$ has also induced the release of the three chemokines (Figure 2). However, there were no significant differences in chemokine levels induced by stimulation of Tumor CM-generated CAFs with TNF- $\alpha$ when compared with stimulation of MSCs by TNF- $\alpha$ (two right-hand bars in Figure 2). These results indicate that Tumor CM did not cooperate with TNF- $\alpha$ in upregulating chemokine release and did not have much of an added value. TNF- $\alpha$ thus had a dominant role in inducing the inflammatory traits in Tumor CM-generated CAFs and in MSCs. Moreover, TNF- $\alpha$ induced the release of the inflammatory chemokines even when the Tumor $\mathrm{CM}$ alone (as shown in Figure 1 for CCL 5 stimulation by MDA CM and for CXCL8 and CCL5 stimulation by MCF-7 CM) had no effect. These results indicate that the different chemokines are commonly regulated by TNFo, unlike their differential response to breast Tumor CM.

These findings suggest that, following their recruitment to the tumor site, MSCs are exposed to tumor constituents that promote their differentiation to CAFs and to some extent can also elevate their ability to release pro-malignancy chemokines. However, since the TME is enriched with TNF- $\alpha$ released by the tumor cells, this inflammatory cytokine turns into a most powerful inducer of chemokine release by CAFs. TNF- $\alpha$ thus enriches the TME with high levels of inflammatory/ tumor-promoting chemokines presenting many deleterious pro-cancerous effects.

To examine the potential clinical relevance of these observations we tested the content of inflammatory chemokines in CAFs obtained directly from a lung metastasis of a breast cancer patient (CAFs \#1) and from a different patient's primary breast tumor (CAFs \#2). Two such CAF isolates showed production of CCL2 and of CXCL8 (Figure 3A1 and 3B1, respectively). Both patient CAF isolates did not secrete CCL5 (Figure 3A1,B1).

To better understand the regulation of chemokine release by patient CAFs, we asked whether CCL 5 - which was not released constitutively by these cells - would be upregulated by inflammatory cytokines such as TNF- $\alpha$ and IL- $1 \beta$ that are known to prevail at the TME of breast tumors. Indeed, in line with the expression of both TNF-RI and TNF-RII by the two patient CAF 


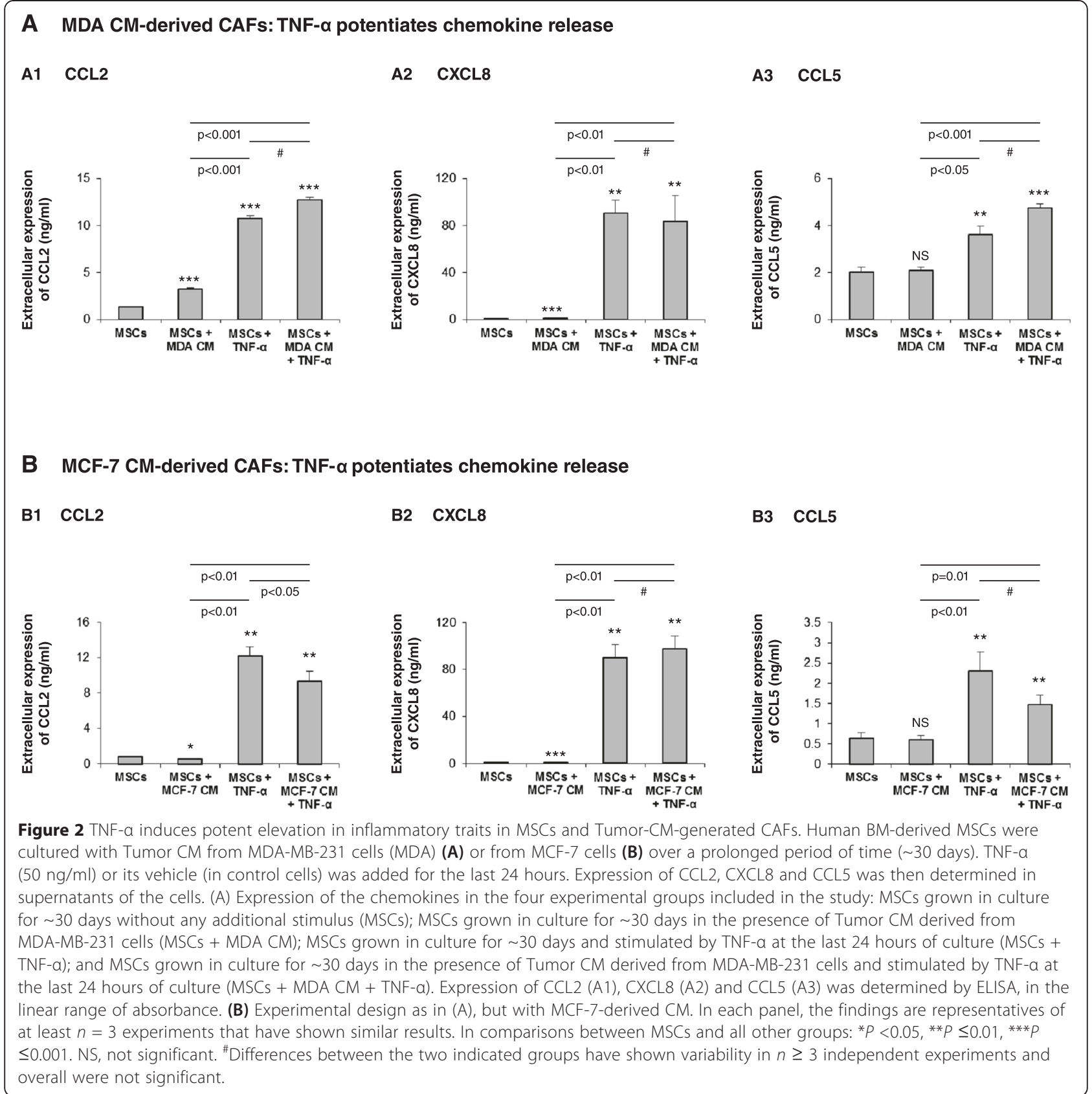

isolates (Figure S3 in Additional file 1), both isolates responded to TNF- $\alpha$ with increased release of CCL5 (Figure 3A2,B2). Similar upregulation of CCL5 expression was observed after stimulation by IL-1 $\beta$ (Figure 3A2,B2), suggesting that chemokine induction by inflammatory cytokines may be a general effect and not necessarily limited to TNF- $\alpha$. These findings support the clinical relevance of our previous findings, showing that TNF- $\alpha$ upregulated CCL5 in CAFs generated from MSCs by MDA Tumor CM (Figure 2A3) and by MCF-7 Tumor CM (Figure 2B3), and suggest that they reflect the clinical conditions of breast cancer.

Overall, the results obtained in this part of the study indicate that while tumor constituents had marginal effects on the inflammatory traits of Tumor CM-generated CAFs, the effects of the inflammatory microenvironment - represented here by TNF- $\alpha$ - were more prominent and may lead to pronounced upregulation of inflammatory chemokines in the TME. TNF- $\alpha$ and IL- $1 \beta$ highly prevail in breast tumors, and thus the inflammatory 


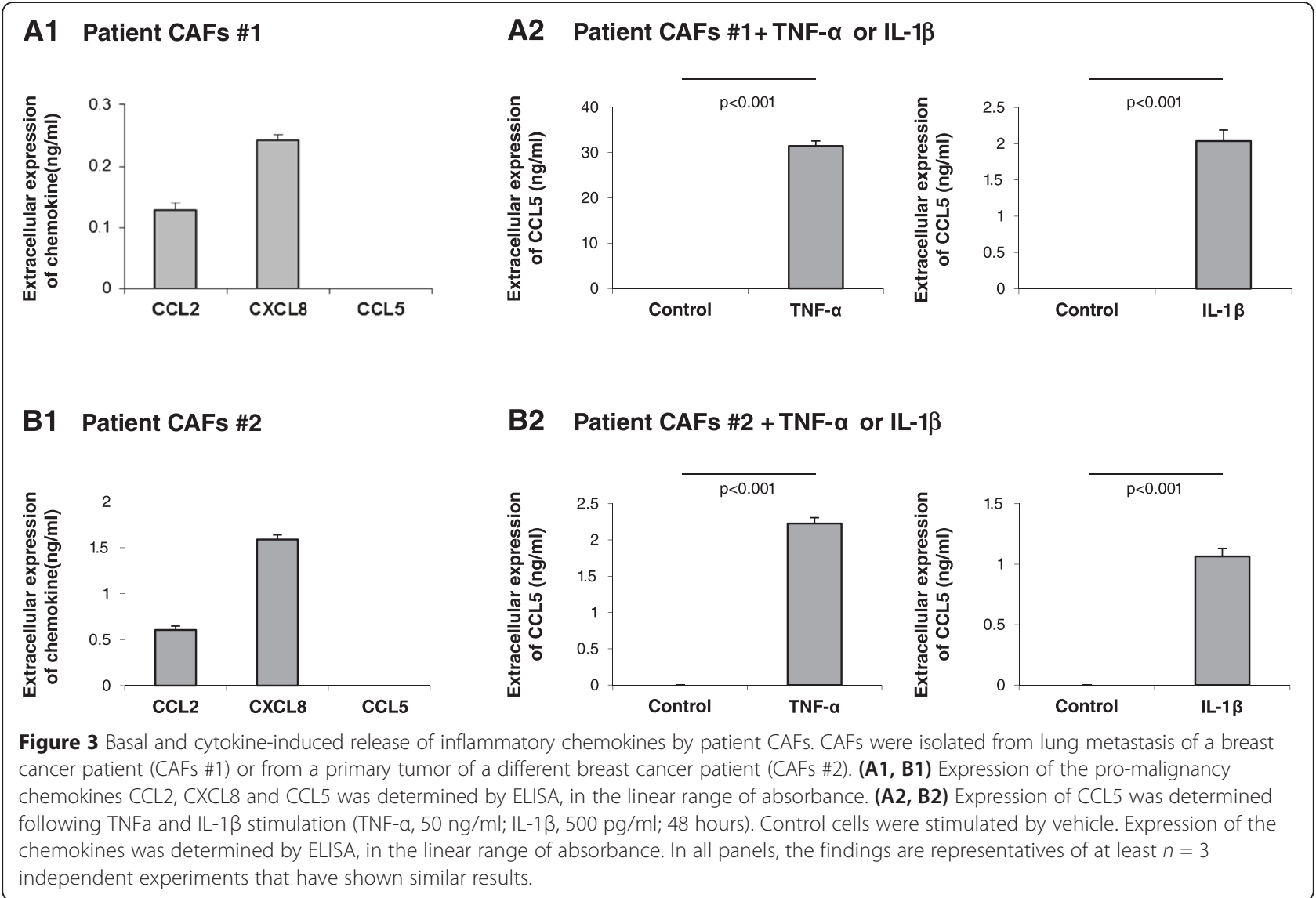

phenotype gained by patient CAFs in response to such inflammatory cytokines may form the basis of inflammation-stroma associations that promote breast cancer progression in patient tumors.

\section{TNF- $\alpha$ amplifies the inflammatory phenotype of MSCs by activating TNF-RI and TNF-RII}

MSCs that populate tumors are candidates for activation by inflammatory factors that are present at the TME. The findings shown in Figure 4A indicate that, following stimulation by TNF- $\alpha$, CXCL8 was the chemokine most prominently induced in MSCs, followed by CCL2 and then CCL5, which underwent relatively low levels of induction. Moreover, the elevations in CCL2, CXCL8 and CCL5 production obtained in TNF- $\alpha$-stimulated MSCs were recapitulated by CM of MDA-MB-231 breast tumor cells that were transfected to express TNF- $\alpha$ (Figure S5 in Additional file 1). Specifically, TNF- $\alpha$ expression by the tumor cells led to prominent upregulation of CCL2, CXCL8 and CCL5 production by MSCs (Figure S5 in Additional file 1). The inflammatory impact was not limited to TNF- $\alpha$ but was also detected following stimulation of MSCs by exogenous IL-1 $\beta$ (Figure S6 in Additional file 1). Overall, all three chemokines - CCL2, CXCL8 and
CCL5 - were induced in MSCs by the inflammatory cytokines TNF- $\alpha$ and IL-1 $\beta$, suggesting that they all may be upregulated in the TME by inflammatory mediators that are highly prevalent at breast tumor sites.

Of the three chemokines induced in MSCs by TNF- $\alpha$, CCL2 was of most interest to us. This chemokine is highly versatile and promotes the inflammatory and procancerous nature of the TME by acting at many divergent levels, not all shared by CXCL8 and CCL5. Furthermore, CCL2 has very high relevance to our current study because we discovered that it was expressed by CAFs residing in proximity to human cancer cells in biopsies of invasive ductal carcinoma (IDC) patients (Figure 5). To further understand the molecular mechanisms mediating inflammation-stroma interactions, we focused on the mechanisms mediating the process of TNF- $\alpha$-induced CCL2 secretion by MSCs. Using neutralizing antibodies to TNF-RI and to TNF-RII, the secretion of CCL2 was significantly inhibited compared with isotype-treated controls (Figure 4B; inhibition of TNF-RI gave rise to 36 to $55 \%$ reduction in CCL2 secretion and inhibition of TNF-RII to 34 to $54 \%$ reduction), indicating that both receptors mediate the effects of TNF- $\alpha$ on CCL2 release by MSCs (based on analyses combining the two antibodies 


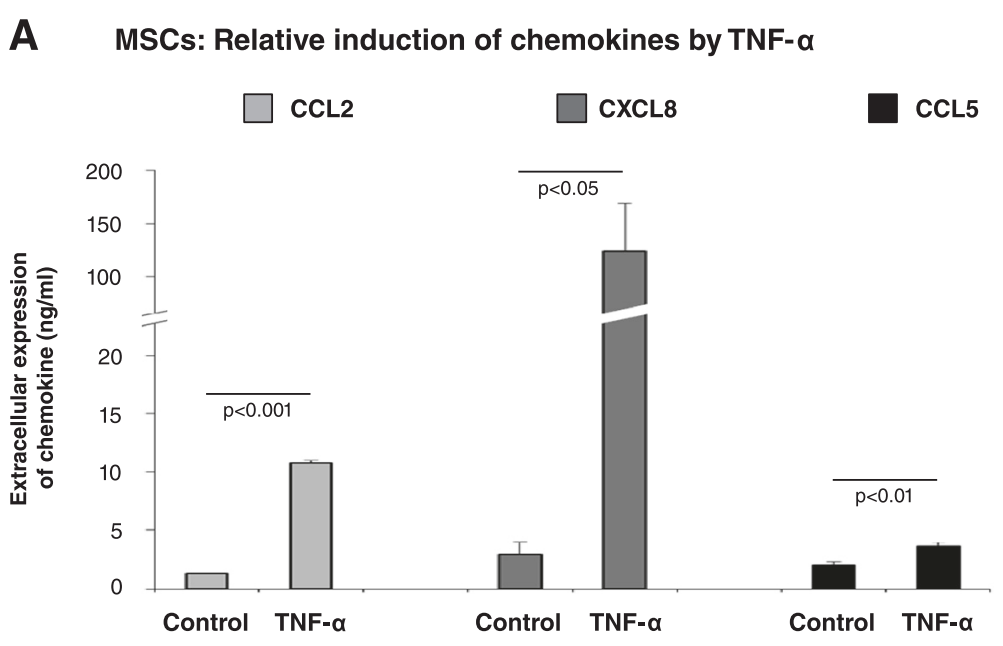

B MSCs:TNF- $\alpha$ receptors

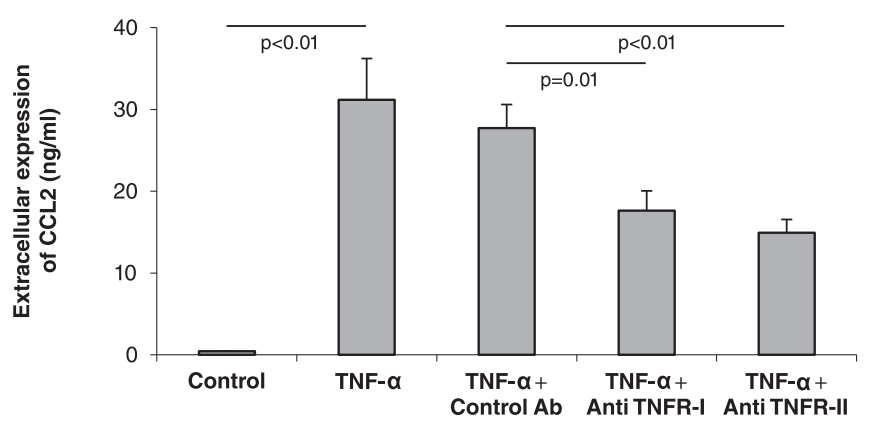

Figure 4 TNF-a upregulates the inflammatory profile of MSCs via receptors TNF-RI and TNF-RII. (A) Relative induction of CCL2, CXCL8 and CCL5 in MSCs by TNF-a. Human BM-derived MSCs were stimulated by TNF-a $(50 \mathrm{ng} / \mathrm{ml})$ for 24 hours and the expression of the inflammatory chemokines CCL2, CXCL8 and CCL5 in supernatants of MSCs was determined by ELISA, in the linear range of absorbance. Results are from an experiment in which all three chemokines were analyzed in parallel, and the ratios between the three chemokines are representatives of the values obtained in many experimental repeats. (B) Human BM-derived MSCs were exposed to neutralizing antibodies against tumor necrosis factor receptors TNF-RI and TNF-RIl or nonrelevant isotype-matched control antibodies (Control Ab) 1 hour prior to stimulation with TNF-a (50 ng/ml), and in the course of 24 hours of stimulation by the cytokine. Control, cells stimulated with vehicle. Expression of CCL2 was determined by ELISA, in the linear range of absorbance. The findings are representatives of at least $n=3$ independent experiments that have shown similar results.

at different concentrations (data not shown), we believe that the inhibition levels could not reach higher levels due to insufficient neutralizing activities of the antibodies). These findings are of major interest because TNF-RI is abundant in most cell types, while the expression of TNFRII is not as promiscuous but nevertheless was found to be upregulated in breast cancer [44,88-91].

\section{Induction of inflammatory traits in MSCs by TNF-a is tightly regulated by the NF-KB pathway}

The AP-1 and NF-kB transcription factors are known to induce the expression of inflammatory chemokines in the immune context; however, their extent of involvement in inducing such chemokines depends on the cell type and stimulus. From the therapeutic perspective it is crucial to know whether both or only one of these transcription factors are mediating the response of MSCs to inflammatory stimuli that give rise to increased production of pro-malignancy chemokines. We began this part of the study by determining the involvement of AP- 1 in induction of CCL2 and CXCL8, the two inflammatory chemokines that we found to be most relevant to the clinical setting, as shown by their expression by patient CAF isolates \#1 and \#2 (Figure 3). While AP-1 was activated by TNF- $\alpha$ stimulation of MSCs, it did not play a role in inducing CCL2 and CXCL8 (Figure 6). Specifically, in response to TNF- $\alpha$, c-Jun - the active component of AP-1 - was rapidly induced in MSCs (possibly due to elevated stability), as was the phosphorylated form of cJun (Figure 6A). However, downregulation of c-Jun 


\section{A CCL2 expression in CAFs: IDC \#1}

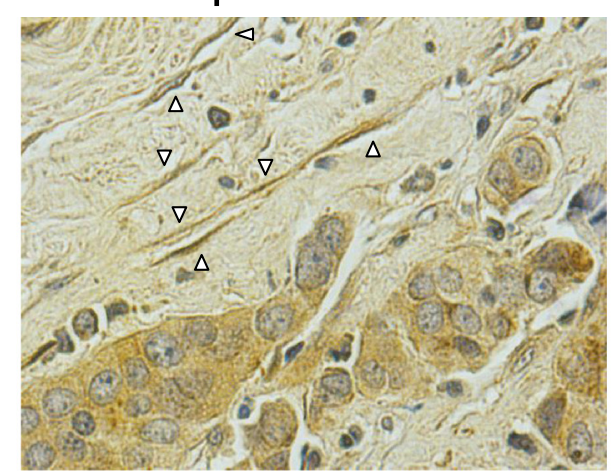

\section{B CCL2 expression in CAFs: IDC \#2}

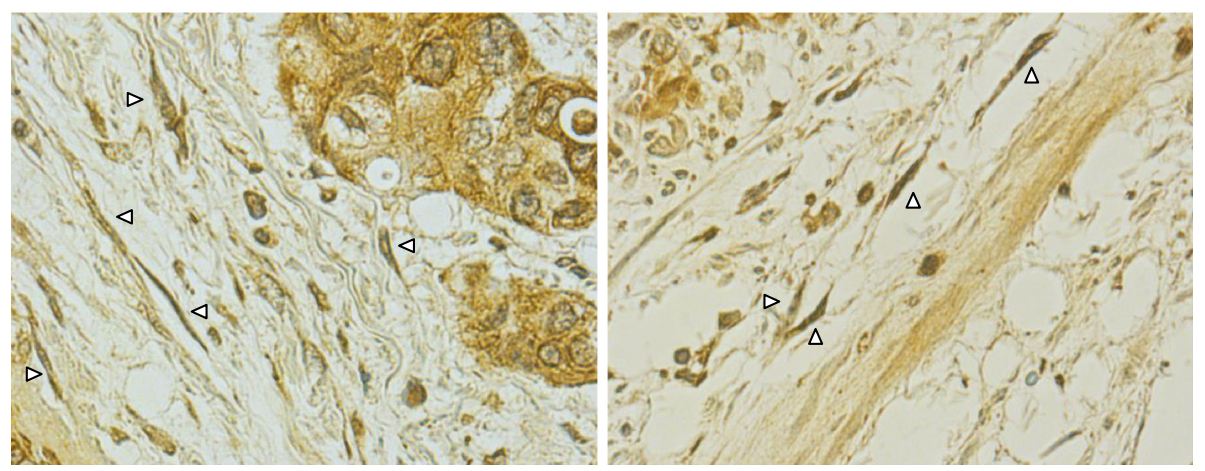

Figure 5 CCL2 is expressed by CAFs localized in vicinity to breast cancer cells in tumors of invasive ductal carcinoma (IDC) patients. CCL2 expression was determined by immunohistochemistry in biopsy sections of patients diagnosed with IDC: (A) IDC \#1, (B) IDC \#2. CCL2 staining was detected in cancer cells and in adjacent fibroblasts. Some of the CCL2-expressing CAFs are indicated by arrows.

expression by siRNA (Figure 6B1) did not lead to reduction in CCL2 and CXCL8 expression following TNF- $\alpha$ stimulation (Figure 6B2; impact on CCL2 was in the range of $21 \%$ inhibition to $33 \%$ increase and for CXCL8 was in the range of $29 \%$ inhibition to $27 \%$ increase).

Different results were obtained for NF-kB, showing that this transcription factor is cardinal in CCL2 and CXCL8 upregulation by TNF- $\alpha$ in MSCs. First, we found that TNF- $\alpha$ stimulation induced significant reduction in the expression levels of $\mathrm{I} \kappa \mathrm{B} \alpha$, the negative regulator of the NF-kB pathway, in MSCs (Figure 7A). Similar results were obtained in TNF- $\alpha$-stimulated Tumor CM-derived CAFs, as well as in patient CAFs (Figure 7B,C). In parallel, p65 was activated by TNF- $\alpha$ stimulation of MSCs (Figure 7D) and direct roles for NF-kB in CCL2 and CXCL8 induction were revealed when p65 was downregulated by siRNA to p65 (Figure 7E1). Specifically, p65 knockdown by siRNA resulted in almost complete inhibition of CCL2 (78 to 88\%) and CXCL8 (82 to 90\%) release by TNF- $\alpha$-stimulated MSCs (Figure 7E2).

In contrast to the results obtained with TNF- $\alpha$ stimulation, a different pattern was obtained with regards to the impact of Tumor CM on the cells: while factors released by tumor cells resulted in MSC conversion to CAFs (Figure S2 in Additional file 1) and to elevated release of some of the inflammatory chemokines (Figure 1), no activation of the NF- $\mathrm{kB}$ pathway was observed in MSCs exposed to Tumor CM (Figure 7B). Here, we need to take into account the fact that the cells were exposed to Tumor CM for 1 month and thus it is possible that the rapid NF- $\mathrm{kB}$ activation signals could no longer be detected.

To summarize, the results of this part of the study clearly indicate an NF-kB-based pathway that regulates the expression of inflammatory and pro-malignancy chemokines such as CCL2 and CXCL8 in MSCs and in CAFs in response to TNF- $\alpha$. NF- $\kappa$ B, but not AP-1, was involved in TNF- $\alpha$-induced inflammatory patterns of CAFs and MSCs, despite the fact that the promoter domains of both these chemokines contain binding sites for c-Jun. This dichotomy between the NF-kB and AP-1 transcription factors in controlling CCL2 and CXCL8 production in MSCs indicates that the inflammatory profile of MSCs is tightly regulated. The preference of one transcription factor over another needs to be considered when potential therapeutic measures are directed to intracellular 


\section{A MSCs: c-Jun up-regulation}

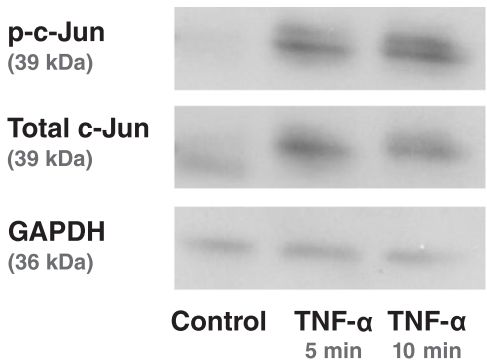

B1 MSCs: c-Jun siRNA - c-Jun expression

Total c-Jun

(39 kDa)

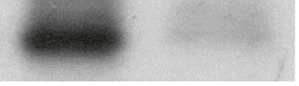

$\beta$-tubulin

$(51 \mathrm{kDa})$

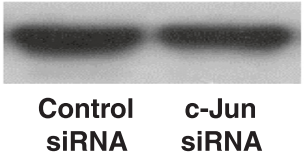

\section{B2 MSCs: c-Jun siRNA -Chemokine secretion}
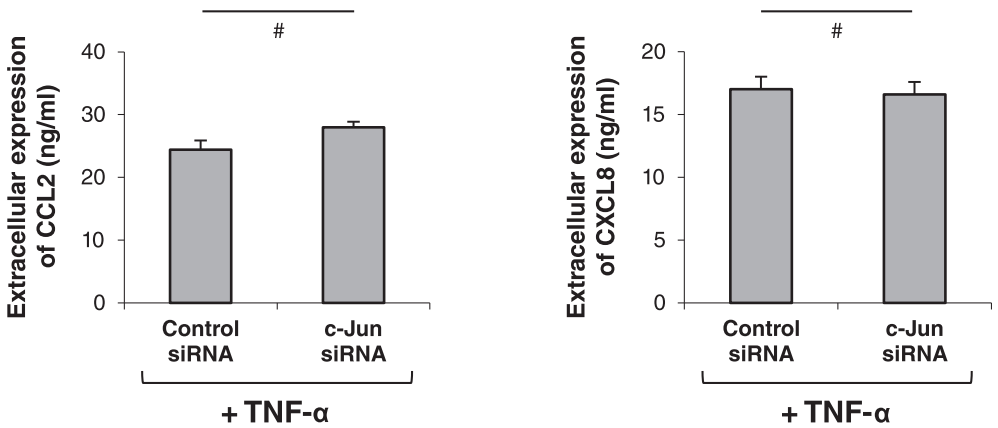

Figure $\mathbf{6}$ Induction of CCL2 and CLXL8 in TNFa-stimulated MSCs is not mediated via the AP-1 pathway. (A) Human BM-derived MSCs were stimulated by TNF-a $(50 \mathrm{ng} / \mathrm{ml})$ for 5 and 10 minutes. Control cells were treated by the vehicle of TNF-a. c-Jun levels and phosphorylation were determined by western blot (WB) analyses. Glyceraldehyde 3-phosphate dehydrogenase (GAPDH) was used as loading control. (B) Human BM-derived MSCs were transiently transfected by small interfering RNA (siRNA) to c-Jun or by control siRNA. (B1) c-Jun expression was determined by WB analyses. $\beta$-Tubulin was used as loading control. (B2) Following siRNA transfection, the cells were stimulated by TNF-a (25 $\mathrm{ng} / \mathrm{ml}$; in this part of the study we used a suboptimal concentration of TNF-a in order to facilitate detection of inhibitory effects) for 24 hours. Expression levels of CCL2 and CXCL8 in the supernatants of the cells were determined by ELISA, in the linear range of absorbance. " siRNA to c-Jun has yielded minor increases or reductions in CCL2 and CXCL8 secretion in different experiments (see Results and discussion), and thus overall there was no significant effect on CCL2 and CXCL8 secretion. In all panels, the findings are representatives of $n=3$ independent experiments that have shown similar results.

components involved in inflammation-induced tumor progression, such as NF-kB and AP-1.

The inflammatory traits gained by MSCs following stimulation by TNF-a lead to potential pro-cancerous effects

Thus far, we have demonstrated that the inflammatory cytokines TNF- $\alpha$ and IL- $1 \beta$ induced inflammatory traits in CAFs and MSCs; furthermore, we have delineated the molecular mechanisms involved in these processes. To follow on these observations, we asked whether the inflammatory traits induced by TNF- $\alpha$ in MSCs have functional relevance to tumor-promoting events taking place at the TME.

CCL2 induces the recruitment to tumors of myeloid subpopulations that exert prominent pro-cancerous effects, including TAMs and MDSCs [17,67,71-75]. We examined the in vitro migration of monocytic cells and found that it was induced by supernatants of TNF- $\alpha$ stimulated MSCs (Figure 8), which have been previously found to be enriched with CCL2 (Figures 2 and 4A). 


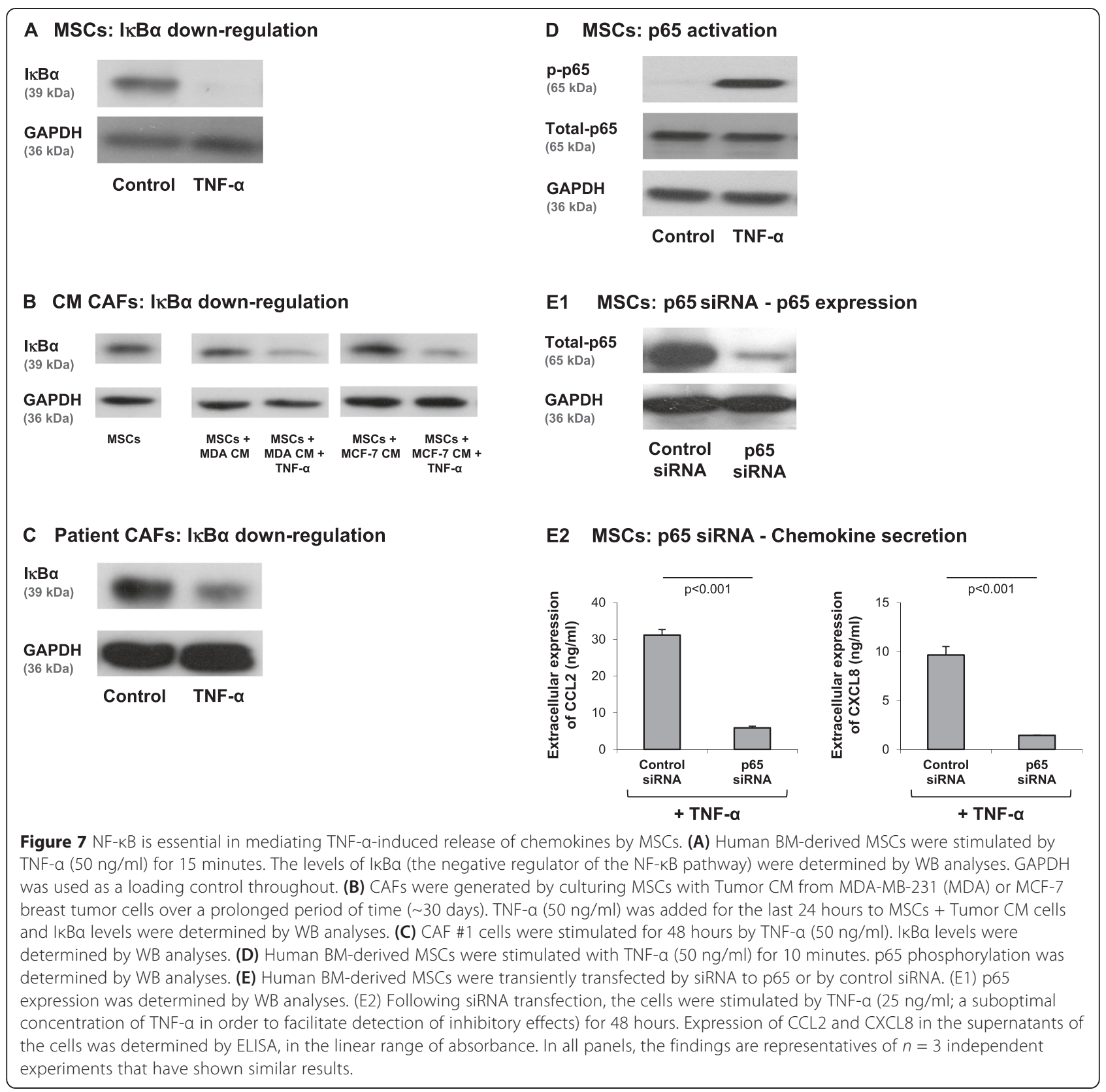

Furthermore, this migratory response was absolutely dependent on CCL2 because neutralization of this chemokine abolished the increase in monocytic cell migration in response to supernatants derived from TNF- $\alpha$-stimulated MSCs (Figure 8 ). These results suggest that TNF- $\alpha$, which is prevalent in the TME, acts on MSCs that reside in the tumors, leading to high production of CCL2 by these cells. This chemokine, in turn, may induce the recruitment of deleterious myeloid infiltrates to the tumor and thus further promote the malignant phenotype of the tumor. Chemokine pro-cancerous activities may thus not only be initiated by the tumor cells directly, but may also be induced by inflammatory factors of the TME acting on stromal cells residing in proximity to the cancer cells.

Furthermore, our findings suggesting that MSC-derived CCL2 promotes the recruitment of TAMs and MDSCs to breast tumors emphasize the important roles of inflammation-stroma interactions. These findings gain high relevance with the fact that CCL2 is indeed expressed in breast cancer cells, as we have shown in our study of biopsies of invasive ductal carcinoma patients (Figure 5). 
MSCs: TNF- $\alpha$ stimulation - CCL2-induced migration of monocytic cells

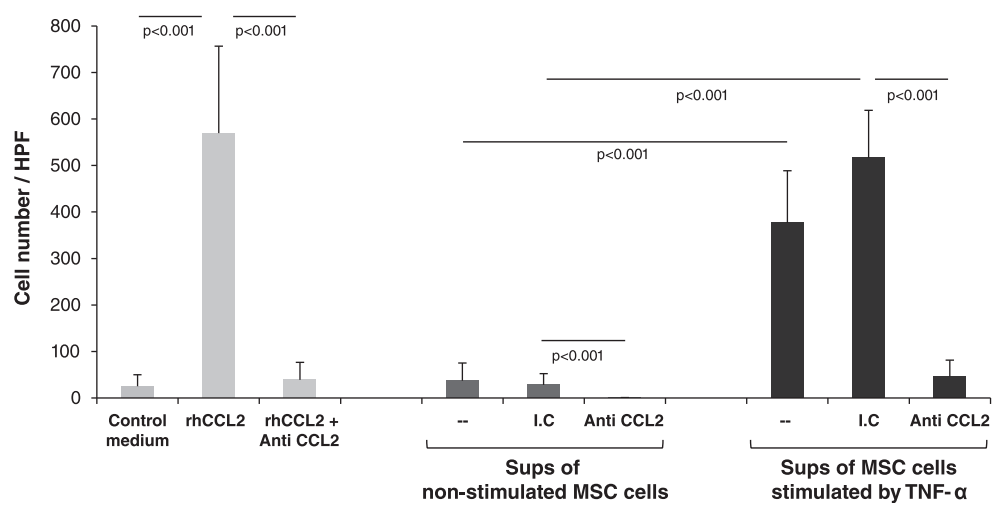

Figure 8 MSCs promote monocyte migration through TNF-a-induced secretion of CCL2. Supernatants (sups) were collected from human BM-derived MSCs that were stimulated by TNF-a $(50 \mathrm{ng} / \mathrm{ml})$ or by its vehicle for 24 hours. Thereafter, the sups were incubated with neutralizing antibodies for CCL2 or with nonrelevant isotype-matched control antibody (I.C.) for 30 minutes. The migration of monocytic cells in response to control medium (without chemokine), to recombinant human CCL2 (rhCCL2; $100 \mathrm{ng} / \mathrm{ml}$ ) or to sups from TNF-a-stimulated or TNF-a nonstimulated MSCs was determined by Boyden chamber migration assays. Cells were counted under a high-power field (HPF). The findings are representatives of $n=3$ independent experiments that have shown similar results.

\section{Conclusions}

Much prominence has been given to inflammationdriven activities that promote tumor progression by acting on cancer cells, infiltrating leukocytes and adjacent stromal cells. In the current study we provide new findings on the networks that control the inflammatory phenotype of CAFs and MSCs, demonstrating key roles for the inflammatory cytokines TNF- $\alpha$ and IL- $1 \beta$ in upregulating the release of inflammatory, tumor-promoting chemokines by these two cell types.

TNF- $\alpha$ and IL- $1 \beta$ are highly relevant to the inflammatory setup of breast tumors [41-49]. They are minimally expressed by normal breast epithelial cells while their expression by breast tumor cells was detected in $\sim 85 \%$ of breast tumors in patients; elevated incidence of TNF- $\alpha$ and IL-1 $\beta$ expression was highly correlated with relapsed and advanced disease [41-49]. In the current study we found that TNF- $\alpha$ upregulated the inflammatory phenotype of Tumor CM-derived CAFs and patient-derived CAFs, manifested by the increased release of CCL2, CXCL8 and CCL5 which are inflammatory chemokines having strong tumor-promoting activities in general and in breast cancer, particularly when derived from stroma cells $[4,21,54-70]$. TNF- $\alpha$ was also demonstrated to be a key inducer of inflammatory characteristics in MSCs, with activities that were much more pronounced and general than those induced by tumor constituents (Tumor CM). As a result of TNF- $\alpha$ stimulation, the stromal cells acquired the ability to release high levels of CCL2, CXCL8 and CCL5. The increased release of these chemokines from CAFs and MSCs may lead to exacerbated inflammatory and pro-cancerous nature of the TME and, based on our results (Figure 8), may lead to increased levels of deleterious myeloid infiltrates in breast tumors. The findings of our study thus suggest that stromal cells located near the cancer cells have a major role in promoting the inflammatory nature of the TME. Overall, a coordinated inflammatory network may be established at the tumor site between the cancer cells and stromal cells, set up by inflammatory cytokines such as TNF- $\alpha$ and IL- $1 \beta$.

In this study we have also revealed the important role of NF- $k B$, but not of AP-1, in mediating the activities of TNF- $\alpha$ on MSCs and CAFs. These findings support other reports $[10,92,93]$, indicating that the NF- $\mathrm{B}$ pathway is a key cellular component that controls inflammatory events at the TME. The ultimate need for NF- $\mathrm{kB}$ activation in this process provides novel insights into specificity in regulatory pathways and may thus have clinical therapeutic implications. This need shows that NF-kB may be a preferred target for inhibition and that its roles are not limited to the tumor cells themselves and to infiltrating leukocytes $[94,95]$, but rather extend to stromal cells at the tumor milieu. Thus, our study strongly supports the positioning of $\mathrm{NF}-\mathrm{kB}$ as a master regulator that may serve as a therapeutic target, whose inhibition may lead to significant downregulation of inflammatory, procancerous events in the entire tumor.

Currently, the inhibition of NF-kB in cancer has not entered the stage of clinical trials, and may be hampered by the fact that this pathway regulates a number of essential cellular processes and immune activities. Such hurdles can be overcome by directing the NF-kBinhibiting modalities to specific target cells, in which this transcription factor is the key inducer of undesired inflammatory, tumor-promoting effects. In this respect, 
the results of our study imply that MSCs and CAFs could serve as appropriate targets for NF- $\mathrm{KB}$ inhibition, through which downregulation of the inflammatory TME could be achieved.

\section{Additional file}

\section{Additional file 1: Presents the following additional data. Figure S1.}

verifying the purity and mesenchymal phenotype of patient-derived CAF isolates. Figure S2. showing that human BM-derived MSCs, exposed for $\sim 30$ days to Tumor CM, undergo transition to CAFs. Figure S3. showing that TNF-RI and TNF-RII are expressed by human BM-derived MSCs and by patient-derived CAFs. Figure S4. showing that breast tumor cells transfected with TNF-a-expressing vector release high TNF-a levels. Figure S5. showing that TNF-a produced by breast tumor cells induces chemokine release by MSCs. Figure $\mathbf{S 6}$. showing that stimulation by IL-1 $\beta$ upregulates the release of the inflammatory chemokines CCL2, CXCL8 and CCL5 by MSCS.

\section{Abbreviations}

aSMA: a-smooth muscle actin; BM: bone marrow; BSA: bovine serum albumin; CAF: cancer-associated fibroblast; CM: conditioned medium; DMEM: Dulbecco's modified Eagle's medium; ELISA: enzyme-linked immunosorbent assay; FAPa: fibroblast activation protein alpha; FBS: fetal bovine serum; FSP1: fibroblast specific protein 1; GAPDH: glyceraldehyde 3-phosphate dehydrogenase; HPF: high power field; IL: interleukin; IDC: invasive ductal carcinoma; mAb: monoclonal antibody; MDSC: myeloid-derived suppressor cell; MSC: mesenchymal stem/stromal cell; NF: nuclear factor; siRNA: small interfering RNA; TAM: tumor-associated macrophage; TME: tumor microenvironment; TNF-a: tumor necrosis factor alpha; TNF-R: tumor necrosis factor receptor; WB: western blot.

\section{Competing interests}

The authors declare that they have no competing interests.

\section{Authors' contributions}

$\mathrm{CK}$ and SL were the major contributors to the acquisition of data and performed most of the experiments included in the study. GS-A and YL were involved in immunohistochemical studies of patient biopsies that were analyzed by the pathologist LL-T. JB and RF-B generated the patient CAFs used in the study and IK contributed to their characterization. HK participated in studies on AP-1. TM analyzed the expression of TNF-a receptors by PCR. DB was instrumental in setting up the research system of CAFs and MSCs and was involved in the study design during the initial stages of research. AB-B was the principal investigator responsible for the whole study, including all its parts. All authors read and approved the manuscript.

\section{Authors' information}

AB-B's research contributed to the currently widely-accepted view on chemokines as key regulators of malignancy, particularly breast cancer. Based on her publications (cited by over 3,300 papers, not including self-citations), the National Institutes of Health included the chemokine CCL5 in the Central Biomarker Repository (SCan-Mark). Currently, the research in AB-B's laboratory is devoted to basic aspects of inflammation-driven events in breast cancer and to the design of inhibitory modalities that inhibit such processes. AB-B is a full professor, heading the Ela Kodesz Institute for Research on Cancer Development and Prevention in Tel Aviv University. As of September 2013, she acts as Head of Department of Cell Research and Immunology, Faculty of Life Sciences, Tel Aviv University.

DB's research contributed to the in vitro model of CAFs generated from BM-derived MSCs that have been used by investigators to study tumor-stroma interactions. Currently, research in the Banerjee group is directed toward understanding the role of monocarboxylates such as lactate and pyruvate and their respective transporters in tumor-stroma interaction in the TME. DB is an Associate Professor of Medicine and Pharmacology at RWJMS, Rutgers University and an Assistant Dean of Global Initiatives at the Graduate School of Biomedical Sciences at Rutgers University.

$\mathrm{DB}$ and $\mathrm{AB}-\mathrm{B}$ are equal contributors as principal investigators.

\section{Acknowledgements}

This study was supported by the Israel Academy of Sciences, Israel Cancer Association, DKFZ-MOST Foundation and Federico Foundation.

\section{Author details}

'Department of Cell Research and Immunology, George S. Wise Faculty of Life Sciences, Tel Aviv University, P.O. Box 39040, Tel Aviv 6997801, Israel. ${ }^{2}$ Department of Pathology, Tel Aviv Sourasky Medical Center and the Sackler School of Medicine, Tel Aviv University, 6 Weizmann Street, Tel Aviv 64239, Israel. Institute of Oncology, Sheba Medical Center, Tel-Hashomer, Ramat Gan 5262100, Israel. ${ }^{4}$ Department of Medicine and Pharmacology, Robert Wood Johnson Medical School and Graduate School of Biomedical Sciences, Rutgers, The State University of New Jersey, 195 Little Albany Street, New Brunswick, NJ 08901, USA.

Received: 14 October 2014 Revised: 14 October 2014 Accepted: 13 April 2015 Published online: 01 May 2015

\section{References}

1. Trimboli AJ, Cantemir-Stone CZ, Li F, Wallace JA, Merchant A, Creasap N, et al. Pten in stromal fibroblasts suppresses mammary epithelial tumours Nature. 2009:461:1084-91.

2. Al-Rakan MA, Colak D, Hendrayani SF, Al-Bakheet A, Al-Mohanna FH, Kaya N, et al. Breast stromal fibroblasts from histologically normal surgical margins are pro-carcinogenic. J Pathol. 2013;231:457-65.

3. Yashiro M, Ikeda K, Tendo M, Ishikawa T, Hirakawa K. Effect of organ-specific fibroblasts on proliferation and differentiation of breast cancer cells. Breast Cancer Res Treat. 2005;90:307-13.

4. Hembruff SL, Jokar I, Yang L, Cheng N. Loss of transforming growth factor-beta signaling in mammary fibroblasts enhances CCL2 secretion to promote mammary tumor progression through macrophage-dependent and -independent mechanisms. Neoplasia. 2010;12:425-33.

5. Bergfeld SA, DeClerck YA. Bone marrow-derived mesenchymal stem cells and the tumor microenvironment. Cancer Metastasis Rev. 2010;29:249-61.

6. Quante M, Tu SP, Tomita H, Gonda T, Wang SS, Takashi S, et al. Bone marrow-derived myofibroblasts contribute to the mesenchymal stem cell niche and promote tumor growth. Cancer Cell. 2011:19:257-72.

7. Spaeth EL, Labaff AM, Toole BP, Klopp A, Andreeff M, Marini FC. Mesenchymal CD44 expression contributes to the acquisition of an activated fibroblast phenotype via TWIST activation in the tumor microenvironment. Cancer Res. 2013;73:5347-59.

8. Guo X, Oshima H, Kitmura T, Taketo MM, Oshima M. Stromal fibroblasts activated by tumor cells promote angiogenesis in mouse gastric cancer. J Biol Chem. 2008;283:19864-71.

9. Lin SY, Dolfi SC, Amiri S, Li J, Budak-Alpdogan T, Lee KC, et al. P53 regulates the migration of mesenchymal stromal cells in response to the tumor microenvironment through both CXCL12-dependent and -independent mechanisms. Int J Oncol. 2013:43:1817-23.

10. Uchibori R, Tsukahara T, Mizuguchi H, Saga Y, Urabe M, Mizukami H, et al. NF-kappaB activity regulates mesenchymal stem cell accumulation at tumor sites. Cancer Res. 2012;73:364-72.

11. Shangguan $L$, Ti X, Krause U, Hai B, Zhao Y, Yang Z, et al. Inhibition of TGF-beta/Smad signaling by BAMBI blocks differentiation of human mesenchymal stem cells to carcinoma-associated fibroblasts and abolishes their protumor effects. Stem Cells. 2012;30:2810-9.

12. Spaeth EL, Dembinski JL, Sasser AK, Watson K, Klopp A, Hall B, et al. Mesenchymal stem cell transition to tumor-associated fibroblasts contributes to fibrovascular network expansion and tumor progression. PLoS One. 2009;4, e4992.

13. Mishra PJ, Humeniuk R, Medina DJ, Alexe G, Mesirov JP, Ganesan S, et al. Carcinoma-associated fibroblast-like differentiation of human mesenchymal stem cells. Cancer Res. 2008:68:4331-9.

14. Jotzu C, Alt E, Welte G, Li J, Hennessy BT, Devarajan E, et al. Adipose tissue derived stem cells differentiate into carcinoma-associated fibroblast-like cells under the influence of tumor derived factors. Cell Oncol (Dordr). 2011;34:55-67.

15. Colotta F, Allavena P, Sica A, Garlanda C, Mantovani A. Cancer-related inflammation, the seventh hallmark of cancer: links to genetic instability. Carcinogenesis. 2009;30:1073-81.

16. Qian BZ, Pollard JW. Macrophage diversity enhances tumor progression and metastasis. Cell. 2010;141:39-51. 
17. Sica A, Porta C, Morlacchi S, Banfi S, Strauss L, Rimoldi M, et al. Origin and functions of tumor-associated myeloid cells (TAMCs). Cancer Microenviron. 2011;5:133-49.

18. Grivennikov SI, Greten FR, Karin M. Immunity, inflammation, and cancer. Cell. 2010;140:883-99.

19. Balkwill F. Tumour necrosis factor and cancer. Nat Rev Cancer. 2009;9:361-71.

20. Bertazza $L$, Mocellin S. The dual role of tumor necrosis factor (TNF) in cancer biology. Curr Med Chem. 2010;17:3337-52.

21. Ben-Baruch A. The tumor-promoting flow of cells into, within and Out of the tumor site: regulation by the inflammatory axis of TNFalpha and chemokines. Cancer Microenviron. 2012;5:151-64.

22. Romieu-Mourez R, Francois M, Abate A, Boivin MN, Birman E, Bailey D, et al. Mesenchymal stromal cells expressing ErbB-2/neu elicit protective antibreast tumor immunity in vivo, which is paradoxically suppressed by IFN-gamma and tumor necrosis factor-alpha priming. Cancer Res. 2010;70:7742-7.

23. Warren MA, Shoemaker SF, Shealy DJ, Bshar W, Ip MM. Tumor necrosis factor deficiency inhibits mammary tumorigenesis and a tumor necrosis factor neutralizing antibody decreases mammary tumor growth in neu/erbB2 transgenic mice. Mol Cancer Ther. 2009;8:2655-63.

24. Houghton J, Li H, Fan X, Liu Y, Liu JH, Rao VP, et al. Mutations in bone marrow-derived stromal stem cells unmask latent malignancy. Stem Cells Dev. 2010;19:1153-66.

25. Sangaletti S, Tripodo C, Ratti C, Piconese S, Porcasi R, Salcedo R, et al. Oncogene-driven intrinsic inflammation induces leukocyte production of tumor necrosis factor that critically contributes to mammary carcinogenesis. Cancer Res. 2010;70:7764-75.

26. Hamaguchi T, Wakabayashi H, Matsumine A, Sudo A, Uchida A. TNF inhibitor suppresses bone metastasis in a breast cancer cell line. Biochem Biophys Res Commun. 2011:407:525-30.

27. Rubio MF, Werbajh S, Cafferata EG, Quaglino A, Colo GP, Nojek IM, et al. TNF-alpha enhances estrogen-induced cell proliferation of estrogen-dependent breast tumor cells through a complex containing nuclear factor-kappa B. Oncogene. 2006;25:1367-77.

28. Rivas MA, Tkach M, Beguelin W, Proietti CJ, Rosemblit C, Charreau EH, et al. Transactivation of ErbB-2 induced by tumor necrosis factor alpha promotes NF-kappaB activation and breast cancer cell proliferation. Breast Cancer Res Treat. 2009;122:111-24

29. Rivas MA, Carnevale RP, Proietti CJ, Rosemblit C, Beguelin W, Salatino M, et al. TNF alpha acting on TNFR1 promotes breast cancer growth via p42/P44 MAPK, JNK, Akt and NF-kappa B-dependent pathways. Exp Cell Res. 2008:314:509-29.

30. Apte RN, Voronov E. Is interleukin-1 a good or bad 'guy' in tumor immunobiology and immunotherapy? Immunol Rev. 2008;222:222-41.

31. Dinarello CA. Why not treat human cancer with interleukin-1 blockade? Cancer Metastasis Rev. 2010;29:317-29.

32. Lewis AM, Varghese $\mathrm{S}, \mathrm{Xu} \mathrm{H}$, Alexander HR. Interleukin-1 and cancer progression: the emerging role of interleukin-1 receptor antagonist as a novel therapeutic agent in cancer treatment. J Transl Med. 2006;4:48.

33. Apte RN, Dotan S, Elkabets M, White MR, Reich E, Carmi Y, et al. The involvement of IL-1 in tumorigenesis, tumor invasiveness, metastasis and tumor-host interactions. Cancer Metastasis Rev. 2006;25:387-408.

34. Schmid MC, Avraamides CJ, Foubert P, Shaked Y, Kang SW, Kerbel RS, et al. Combined blockade of integrin-alpha4beta1 plus cytokines SDF-1alpha or IL-1 beta potently inhibits tumor inflammation and growth. Cancer Res. 2011;71:6965-75

35. Zhou W, Guo S, Gonzalez-Perez RR. Leptin pro-angiogenic signature in breast cancer is linked to IL-1 signalling. Br J Cancer. 2011;104:128-37.

36. Palmieri C, Roberts-Clark D, Assadi-Sabet A, Coope RC, O'Hare M, Sunters A et al. Fibroblast growth factor 7 , secreted by breast fibroblasts, is an interleukin-1 beta-induced paracrine growth factor for human breast cells. $J$ Endocrinol. 2003;177:65-81.

37. Naldini A, Filippi I, Miglietta D, Moschetta M, Giavazzi R, Carraro F. Interleukin-1 beta regulates the migratory potential of MDAMB231 breast cancer cells through the hypoxia-inducible factor-1alpha. Eur J Cancer. 2010;46:3400-8

38. Argiles JM, Busquets S, Lopez-Soriano FJ. Anti-inflammatory therapies in cancer cachexia. Eur J Pharmacol. 2011;668:581-6.

39. Balkwill FR, Mantovani A. Cancer-related inflammation: common themes and therapeutic opportunities. Semin Cancer Biol. 2012;22:33-40.
40. Balkwill F, Mantovani A. Cancer and inflammation: implications for pharmacology and therapeutics. Clin Pharmacol Ther. 2010;87:401-6.

41. Soria G, Ofri-Shahak M, Haas I, Yaal-Hahoshen N, Leider-Trejo L, Leibovich-Rivkin T, et al. Inflammatory mediators in breast cancer: Coordinated expression of TNFa \& IL-1 $\beta$ with CCL2 \& CCL5 and effects on epithelial-to-mesenchymal transition. BMC Cancer. 2011:11:130-49.

42. Leek RD, Landers R, Fox SB, Ng F, Harris AL, Lewis CE. Association of tumour necrosis factor alpha and its receptors with thymidine phosphorylase expression in invasive breast carcinoma. Br J Cancer. 1998;77:2246-51.

43. Miles DW, Happerfield LC, Naylor MS, Bobrow LG, Rubens RD, Balkwill FR. Expression of tumour necrosis factor (TNF alpha) and its receptors in benign and malignant breast tissue. Int J Cancer. 1994;56:777-82.

44. Garcia-Tunon I, Ricote M, Ruiz A, Fraile B, Paniagua R, Royuela M. Role of tumor necrosis factor-alpha and its receptors in human benign breast lesions and tumors (in situ and infiltrative). Cancer Sci. 2006;97:1044-9.

45. Cui LF, Guo XJ, Wei J, Liu FF, Fan Y, Lang RG, et al. Overexpression of TNF-alpha and TNFRII in invasive micropapillary carcinoma of the breast: clinicopathological correlations. Histopathology. 2008;53:381-8.

46. Jin L, Yuan RQ, Fuchs A, Yao Y, Joseph A, Schwall R, et al. Expression of interleukin-1beta in human breast carcinoma. Cancer. 1997:80:421-34.

47. Pantschenko AG, Pushkar I, Anderson KH, Wang Y, Miller LJ, Kurtzman $\mathrm{SH}$, et al. The interleukin-1 family of cytokines and receptors in human breast cancer: implications for tumor progression. Int J Oncol. 2003;23:269-84.

48. Kurtzman SH, Anderson KH, Wang Y, Miller LJ, Renna M, Stankus M, et al. Cytokines in human breast cancer: IL-1alpha and IL-1beta expression. Oncol Rep. 1999;6:65-70.

49. Chavey C, Bibeau F, Gourgou-Bourgade S, Burlinchon S, Boissiere F, Laune $D$, et al. Oestrogen receptor negative breast cancers exhibit high cytokine content. Breast Cancer Res. 2007:9:R15.

50. Ren G, Zhao X, Zhang L, Zhang J, L'Huillier A, Ling W, et al. Inflammatory cytokine-induced intercellular adhesion molecule-1 and vascular cell adhesion molecule-1 in mesenchymal stem cells are critical for immunosuppression. J Immunol. 2010;184:2321-8.

51. Ren G, Zhang L, Zhao X, Xu G, Zhang Y, Roberts Al, et al. Mesenchymal stem cell-mediated immunosuppression occurs via concerted action of chemokines and nitric oxide. Cell Stem Cell. 2008:2:141-50.

52. Liu Y, Han ZP, Zhang SS, Jing YY, Bu XX, Wang CY, et al. Effects of inflammatory factors on mesenchymal stem cells and their role in the promotion of tumor angiogenesis in colon cancer. J Biol Chem. 2011;286:25007-15

53. Han Z, Tian Z, Lv G, Zhang L, Jiang G, Sun K, et al. Immunosuppressive effect of bone marrow-derived mesenchymal stem cells in inflammatory microenvironment favours the growth of B16 melanoma cells. J Cell Mol Med. 2011;15:2343-52.

54. Ren G, Zhao X, Wang Y, Zhang X, Chen X, Xu C, et al. CCR2-dependent recruitment of macrophages by tumor-educated mesenchymal stromal cells promotes tumor development and is mimicked by TNFalpha. Cell Stem Cell. 2012;11:812-24.

55. Li HJ, Reinhardt F, Herschman HR, Weinberg RA. Cancer-stimulated mesenchymal stem cells create a carcinoma stem cell niche via prostaglandin E2 signaling. Cancer Discov. 2012;2:840-55.

56. Zhang $Y$, Yang $P$, Sun $T$, Li D, Xu X, Rui Y, et al. miR-126 and miR-126* repress recruitment of mesenchymal stem cells and inflammatory monocytes to inhibit breast cancer metastasis. Nat Cell Biol. 2013;15:284-94.

57. Tsuyada A, Chow A, Wu J, Somlo G, Chu P, Loera S, et al. CCL2 mediates cross-talk between cancer cells and stromal fibroblasts that regulates breast cancer stem cells. Cancer Res. 2012;72:2768-79.

58. Dwyer RM, Potter-Beirne SM, Harrington KA, Lowery AJ, Hennessy E, Murphy $J M$, et al. Monocyte chemotactic protein-1 secreted by primary breast tumors stimulates migration of mesenchymal stem cells. Clin Cancer Res. 2007;13:5020-7.

59. Klopp AH, Spaeth EL, Dembinski JL, Woodward WA, Munshi A, Meyn RE, et al. Tumor irradiation increases the recruitment of circulating mesenchymal stem cells into the tumor microenvironment. Cancer Res. 2007;67:11687-95.

60. Ksiazkiewicz M, Gottfried E, Kreutz M, Mack M, Hofstaedter F, Kunz-Schughart $L A$. Importance of CCL2-CCR2A/2B signaling for monocyte migration into spheroids of breast cancer-derived fibroblasts. Immunobiology. 2010;215:737-47. 
61. Karnoub AE, Dash AB, Vo AP, Sullivan A, Brooks MW, Bell GW, et al. Mesenchymal stem cells within tumour stroma promote breast cancer metastasis. Nature. 2007:449:557-63.

62. Mi Z, Bhattacharya SD, Kim VM, Guo H, Talbot LJ, Kuo PC. Osteopontin promotes CCL5-mesenchymal stromal cell-mediated breast cancer metastasis. Carcinogenesis. 2011;32:477-87.

63. Gallo M, De Luca A, Lamura L, Normanno N. Zoledronic acid blocks the interaction between mesenchymal stem cells and breast cancer cells: implications for adjuvant therapy of breast cancer. Ann Oncol. 2012;23:597-604.

64. Halpern $J$, Kilbarger A, Lynch CC. Mesenchymal stem cells promote mammary cancer cell migration in vitro via the CXCR2 receptor. Cancer Lett. 2011;308:91-9.

65. Welte G, Alt E, Devarajan E, Krishnappa S, Jotzu C, Song YH. Interleukin-8 derived from local tissue-resident stromal cells promotes tumor cell invasion. Mol Carcinog. 2011;51:861-8.

66. Borsig L, Wolf MJ, Roblek M, Lorentzen A, Heikenwalder M. Inflammatory chemokines and metastasis-tracing the accessory. Oncogene. 2013:33:3217-24

67. Huang B, Lei Z, Zhao J, Gong W, Liu J, Chen Z, et al. CCL2/CCR2 pathway mediates recruitment of myeloid suppressor cells to cancers. Cancer Lett. 2007;252:86-92.

68. Gales D, Clark C, Manne U, Samuel T. The chemokine CXCL8 in carcinogenesis and drug response. ISRN Oncol. 2013;2013:859154.

69. Aldinucci D, Colombatti A. The inflammatory chemokine CCL5 and cancer progression. Mediators Inflamm. 2014;2014:292376.

70. Soria G, Ben-Baruch A. The inflammatory chemokines CCL2 and CCL5 in breast cancer. Cancer Lett. 2008:267:271-85.

71. Bonecchi R, Locati M, Mantovani A. Chemokines and cancer: a fatal attraction. Cancer Cell. 2011;19:434-5.

72. Arendt LM, McCready J, Keller PJ, Baker DD, Naber SP, Seewaldt V, et al. Obesity promotes breast cancer by CCL2-mediated macrophage recruitment and angiogenesis. Cancer Res. 2013;73:6080-93.

73. Lu X, Kang Y. Chemokine (C-C motif) ligand 2 engages CCR2+ stromal cells of monocytic origin to promote breast cancer metastasis to lung and bone. J Biol Chem. 2009;284:29087-96.

74. Qian BZ, Li J, Zhang H, Kitamura T, Zhang J, Campion LR, et al. CCL2 recruits inflammatory monocytes to facilitate breast-tumour metastasis. Nature. 2011:475:222-5

75. Yadav A, Saini V, Arora S. MCP-1: chemoattractant with a role beyond immunity: a review. Clin Chim Acta. 2010;411:1570-9.

76. Simstein R, Burow M, Parker A, Weldon C, Beckman B. Apoptosis, chemoresistance, and breast cancer: insights from the MCF-7 cell model system. Exp Biol Med (Maywood). 2003;228:995-1003

77. Lacroix M, Leclerca G. Relevance of breast cancer cell lines as models for breast tumours: an update. Breast Cancer Res Treat. 2004;83:249-89.

78. Buganim Y, Madar S, Rais Y, Pomeraniec L, Harel E, Solomon H, et al. Transcriptional activity of ATF3 in the stromal compartment of tumors promotes cancer progression. Carcinogenesis. 2011;32:1749-57.

79. Beyer EM, MacBeath G. Cross-talk between receptor tyrosine kinase and tumor necrosis factor-alpha signaling networks regulates apoptosis but not proliferation. Mol Cell Proteomics. 2012;11:M111 013292.

80. Wu FY, Ou ZL, Feng LY, Luo JM, Wang LP, Shen ZZ, et al. Chemokine decoy receptor $\mathrm{d} 6$ plays a negative role in human breast cancer. Mol Cancer Res. 2008;6:1276-88

81. Feng LY, Ou ZL, Wu FY, Shen ZZ, Shao ZM. Involvement of a novel chemokine decoy receptor CCX-CKR in breast cancer growth, metastasis and patient survival. Clin Cancer Res. 2009:15:2962-70.

82. Kalluri R, Zeisberg M. Fibroblasts in cancer. Nat Rev Cancer. 2006;6:392-401.

83. Kojima Y, Acar A, Eaton EN, Mellody KT, Scheel C, Ben-Porath I, et al. Autocrine TGF-beta and stromal cell-derived factor-1 (SDF-1) signaling drives the evolution of tumor-promoting mammary stromal myofibroblasts. Proc Nat Acad Sci U S A. 2010;107:20009-14.

84. Lin SY, Yang J, Everett AD, Clevenger CV, Koneru M, Mishra PJ, et al. The isolation of novel mesenchymal stromal cell chemotactic factors from the conditioned medium of tumor cells. Exp Cell Res. 2008:314:3107-17.

85. Neumark E, Cohn MA, Lukanidin E, Witz IP, Ben-Baruch A. Possible co-regulation of genes associated with enhanced progression of mammary adenocarcinomas. Immunol Lett. 2002;82:111-21.

86. Neumark E, Sagi-Assif O, Shalmon B, Ben-Baruch A, Witz IP. Progression of mouse mammary tumors: MCP-1-TNFalpha cross-regulatory pathway and clonal expression of promalignancy and antimalignancy factors. Int J Cancer. 2003:106:879-86

87. Leibovich-Rivkin T, Liubomirski Y, Meshel T, Abashidze A, Brisker D, Solomon $\mathrm{H}$, et al. The inflammatory cytokine TNFalpha cooperates with Ras in elevating metastasis and turns WT-Ras to a tumor-promoting entity in MCF-7 cells. BMC Cancer. 2014:14:158

88. MacEwan DJ. TNF receptor subtype signalling: differences and cellular consequences. Cell Signal. 2002:14:477-92.

89. MacEwan DJ. TNF ligands and receptors - a matter of life and death. Br J Pharmacol. 2002;135:855-75.

90. Mestiri S, Bouaouina N, Ben Ahmed S, Chouchane L. A functional polymorphism of the tumor necrosis factor receptor-II gene associated with the survival and relapse prediction of breast carcinoma. Cytokine. 2005;30:182-7

91. Mestiri S, Bouaouina N, Ahmed SB, Khedhaier A, Jrad BB, Remadi S, et al. Genetic variation in the tumor necrosis factor-alpha promoter region and in the stress protein hsp70-2: susceptibility and prognostic implications in breast carcinoma. Cancer. 2001;91:672-8.

92. Erez N, Truitt M, Olson P, Arron ST, Hanahan D. Cancer-associated fibroblasts are activated in incipient neoplasia to orchestrate tumor-promoting inflammation in an NF-kappaB-dependent manner. Cancer Cell. 2010;17:135-47.

93. Schauer IG, Zhang J, Xing Z, Guo X, Mercado-Uribe I, Sood AK, et al. Interleukin-1beta promotes ovarian tumorigenesis through a p53/NF-kappaB-mediated inflammatory response in stromal fibroblasts. Neoplasia. 2013;15:409-20.

94. DiDonato JA, Mercurio F, Karin M. NF-kappaB and the link between inflammation and cancer. Immunol Rev. 2012;246:379-400.

95. Madonna G, Ullman CD, Gentilcore G, Palmieri G, Ascierto PA. NF-kappaB as potential target in the treatment of melanoma. J Transl Med. 2012;10:53.

\section{Submit your next manuscript to BioMed Central and take full advantage of:}

- Convenient online submission

- Thorough peer review

- No space constraints or color figure charges

- Immediate publication on acceptance

- Inclusion in PubMed, CAS, Scopus and Google Scholar

- Research which is freely available for redistribution 